\title{
Enhancing Performances of Perovskite Solar Cells by Using Zinc Oxide Quantum Dots/Mesoporous Titania Electron Transport Layer
}

\section{Mei Wang}

Hubei University of Technology

Huating Bo

Hubei University of Technology

Qiuyun Fu ( $\nabla$ fuqy@mail.hust.edu.cn )

Huazhong University of Science and Technology

\section{Xinguo Ma}

Hubei University of Technology

\section{Zhengwang Cheng}

Hubei University of Technology

Jing He

Hubei University of Technology

\section{Wei Zou}

Hubei University of Technology

\section{Research Article}

Keywords: mesoscopic perovskite solar cells, surface modification, quantum dots, electron extraction, specific surface area

Posted Date: June 12th, 2021

DOI: https://doi.org/10.21203/rs.3.rs-607253/v1

License: (a) (1) This work is licensed under a Creative Commons Attribution 4.0 International License. Read Full License 


\title{
Enhancing Performances of Perovskite Solar Cells by Using Zinc Oxide Quantum Dots/Mesoporous Titania Electron Transport Layer
}

Mei Wang ${ }^{\dagger}$, Huating $\mathrm{Bo}^{\dagger}$, Qiuyun $\mathrm{Fu}^{* \dagger}$, Xinguo $\mathrm{Ma}^{\dagger}$, Zhengwang Cheng ${ }^{\dagger}$, Jing $\mathrm{He}^{\dagger}$, Wei Zou ${ }^{\dagger}$

$\dagger$ Hubei Engineering Technology Research Center of Energy Photoelectric Device and System, Hubei University of Technology, Wuhan 430068, P. R. China

$\$$ School of Optical and Electronic Information, Engineering Research Center for Functional Ceramics of the Ministry of Education, Huazhong University of Science and Technology, Wuhan 430074, P. R. China

* Corresponding author: fuqy@mail.hust.edu.cn

\begin{abstract}
As the photovoltaic performance of mesoscopic perovskite solar cells (PSCs) is strongly dependent on the interface between perovskite and electron transport layer. Herein, an attempt to load facile processed $\mathrm{ZnO}$ quantum dots (ZQDs) or $\mathrm{TiO}_{2}$ quantum dots (TQDs) into the $\mathrm{mp}-\mathrm{TiO}_{2}$ layer via a simple spin-coating method was first performed. Both of them had huge impact on the morphology of perovskite films, leading to larger perovskite grains. However, the power conversion efficiency (PCE) of these two kinds of QDs modified cells exhibited a different tendency. The champion PCE of ZQDs modified PSCs was remarkably improved from $14.54 \%$ to $17.2 \%$, while that of TQDs modified ones decreased to $11.78 \%$. We demonstrated that the enhanced PCE and short-circuit current $\left(\mathrm{J}_{\mathrm{sc}}\right)$ were attributed to the enlarged grain size and enhanced light absorption of perovskite film, faster electron extraction and transport as well as less recombination for ZQDs modified PSCs, which mainly resulted from the increased active specific surface area. On the contrary, deterioration of TQDs modified PSCs was exactly ascribed to the aggregation of TQDs which sharply decreased the
\end{abstract}


specific surface area of the electron transport layer. The current work provided an efficient and facile way to improve the photovoltaic performance of mesoscopic PSCs.

Keywords: mesoscopic perovskite solar cells, surface modification, quantum dots, electron extraction, specific surface area

\section{Introduction}

Since the organometal trihalide perovskite were reported as photosensitizers for photovoltaic cells, ${ }^{1}$ they have attracted great attention for their low cost, simple manufacturing process and high photovoltaic performance in the field of optoelectronics, especially in the application of perovskite solar cells (PSCs). ${ }^{2}$ The energy conversion efficiency of PSCs has risen from $3 \%{ }^{1}$ to $25.5 \%{ }^{3}$ in just a few years.

Mesoporous structured PSCs, especially those based on mesoporous $\mathrm{TiO}_{2}$ (mp$\mathrm{TiO}_{2}$ ), have been proved to have the highest power conversion efficiency (PCE). Because the $\mathrm{mp}-\mathrm{TiO}_{2}$ has a large specific surface area, it can be used as a scaffold to increase the loading amount of perovskite. In addition, it is in direct contact with perovskite and acts as an electron transport layer (ETL), collecting photoelectrons from perovskite and transmitting them to the front contact. ${ }^{4,5,6}$ Therefore, it will be a possible way to promote the performance of PSCs by increasing the effective specific surface area between the carrier transport layer and the light absorbing layer. 7, 8, 9, 10, 11

Due to the fact that quantum dots (QDs) are only a few nanometers in diameter, they are endowed with large specific surface area. Additionally, due to the influence of quantum confinement effect and edge effect, the band gaps of QDs are adjustable. These characteristics make them possess potential application prospect in the field of PSCs. For instance, in planar heterojunction PSCs, black phosphorus QDs have been used to enhance the hole extraction. ${ }^{12}$ CdSe QDs, graphene QDs and Carbon QDs have respectively been used to modify the ETL to make the perovskite thin films denser or accelerate the extraction rate of electrons. ${ }^{13-15}$ According to this idea, selecting 
appropriate quantum dots to modify the $\mathrm{mp}-\mathrm{TiO}_{2}$ is expected to obtain an idea carrier transport material with large specific surface area, appropriate energy level and high conductivity.

In this thesis, we plan to prepare $\mathrm{ZnO}$ QDs (ZQDs) and $\mathrm{TiO}_{2}$ QDs (TQDs), embedding them into mesoporous scaffolds to increase the specific surface area of mesoporous layer, and finally enhance the light absorption of perovskite layer and accelerate the extraction and transmission of electrons. On the one hand, $\mathrm{ZnO}$ and $\mathrm{TiO}_{2}$ have ever been employed as excellent ETL in the area of PSCs owing to their suitable energy levels. On the other hand, ZQDs and TQDs are easily synthesized, and they can by deposited into mesoporous layer by simple spin coating technique. In addition, $\mathrm{ZnO}$ has a high electron mobility of $115-155 \mathrm{~cm}^{2} \mathrm{~V}^{-1} \mathrm{~s}^{-1},{ }^{16,17}$ which is favorable for electron transport.

With this strategy, ZQDs and TQDs modified mesoscopic PSCs have been prepared. Unexpectedly, the ZQDs modified mesoscopic PSCs showed an enhancement in $\mathrm{PCE}(\mathrm{PCE}=17.20 \%$ ) as compared to unmodified PSCs ( $\mathrm{PCE}=14.54 \%)$, while TQDs modified ones showed an opposite tendency $(\mathrm{PCE}=11.78 \%)$. Further discussions indicated that enhanced light absorption, accelerated electron transport, extraction and less recombination were existed in ZQDs modified PSCs for their increased surface area. On the contrary, because of the aggregation of TQDs on the $\mathrm{mp}-\mathrm{TiO}_{2}$, the pore volume and specific surface area were sharply decreased which ultimately led to the performance deterioration of the TQDs modified PSCs.

\section{Results and discussion}

PSCs with the structure of FTO / blocking $\mathrm{TiO}_{2}(\mathrm{BL}) /$ bare or QDs modified mp$\mathrm{TiO}_{2} / \mathrm{CH}_{3} \mathrm{NH}_{3} \mathrm{PbI}_{3}\left(\mathrm{MAPbI}_{3}\right) /$ hole transport material $(\mathrm{HTM}) / \mathrm{Au}$ were fabricated. The fabrication process of PSC modified by QDs is shown in Figure 1. 


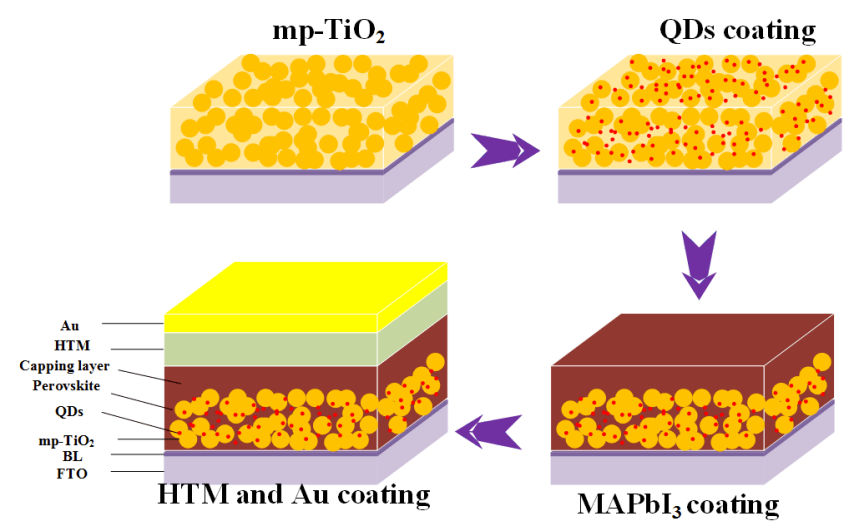

Figure 1. Fabrication process of QDs modified PSCs.
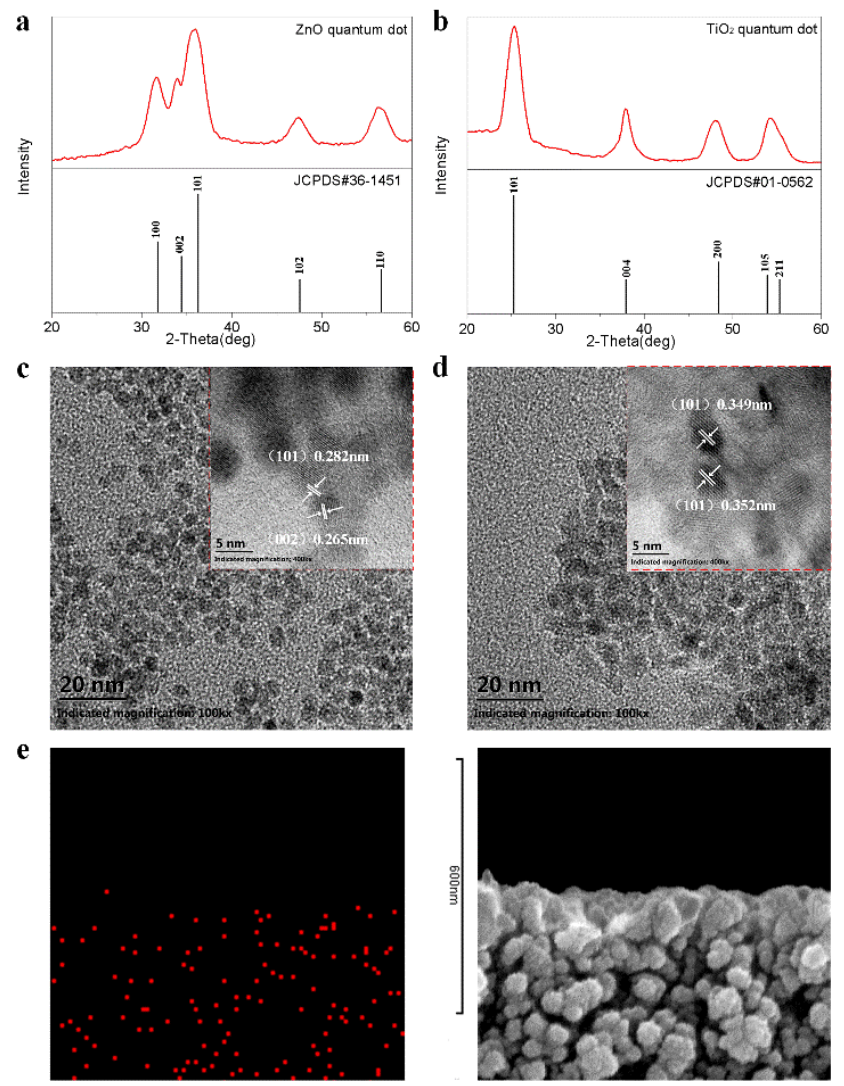

Figure 2. XRD testing results of (a) ZQDs and (b) TQDs; TEM and HRTEM (inset) image of (c) ZQDs and (d) TQDs; (e) distribution of $\mathrm{Zn}$ in $\mathrm{ZQDs} / \mathrm{mp}-\mathrm{TiO}_{2}$ sample obtained from the cross section-scan analysis of EDS mapping images and the corresponding cross section SEM image.

Figure 2a, b represent the X-ray diffraction (XRD) patterns of $\mathrm{ZnO}$ and $\mathrm{TiO}_{2}$ powders obtained by drying solution, which correspond to the hexagonal wurtzite zinc oxide (JCPDS \#36-1451) and the anatase titanium dioxide (JCPDS\#01-0562), 
respectively, without any impurities observed. The evidently broad nature of reflections confirms that particles are in nanoscale. According to the Debye Scherer formula $\mathrm{D}=0.89 \lambda /\left(\beta \cos \theta_{B}\right)$, where $\mathrm{D}$ represents the diameter of particles, $\lambda$ represents the $\mathrm{x}-$ ray wavelength (1.5406 $\AA$ ), $\theta_{B}$ represents the Bragg diffraction angle, and $\beta$ represents the peak width at half maximum, the calculated grain size of $\mathrm{ZnO}$ and $\mathrm{TiO}_{2}$ are about 6 $\mathrm{nm}$ and $7 \mathrm{~nm}$, respectively, indicating the formation of QDs. Transmission electron microscopy (TEM) images (Figure 2c, d) reveal that both the as-prepared ZQDs and TQDs are well-distributed and nearly spherically shaped dots with an average diameter of about $5 \mathrm{~nm}$. High-resolution TEM (HRTEM) image of ZQDs shows the lattice distance of $0.282 \mathrm{~nm}$ and $0.265 \mathrm{~nm}$, corresponding to the (101) and (002) facets. As for the TQDs, a lattice spacing of $0.352 \mathrm{~nm}$ is taken, which is corresponded to the (101) facets of TQDs. Then the as-prepared ZQDs or TQDs were added by spin coating their dispersion solution onto the $\mathrm{mp}-\mathrm{TiO}_{2}$ layers. SEM (scanning electron microscope) and EDS (energy dispersive spectrometer) mapping images shown in Figure 2e indicate a homogeneous distribution of ZQDs in $\mathrm{mp}-\mathrm{TiO}_{2}$ matrix.
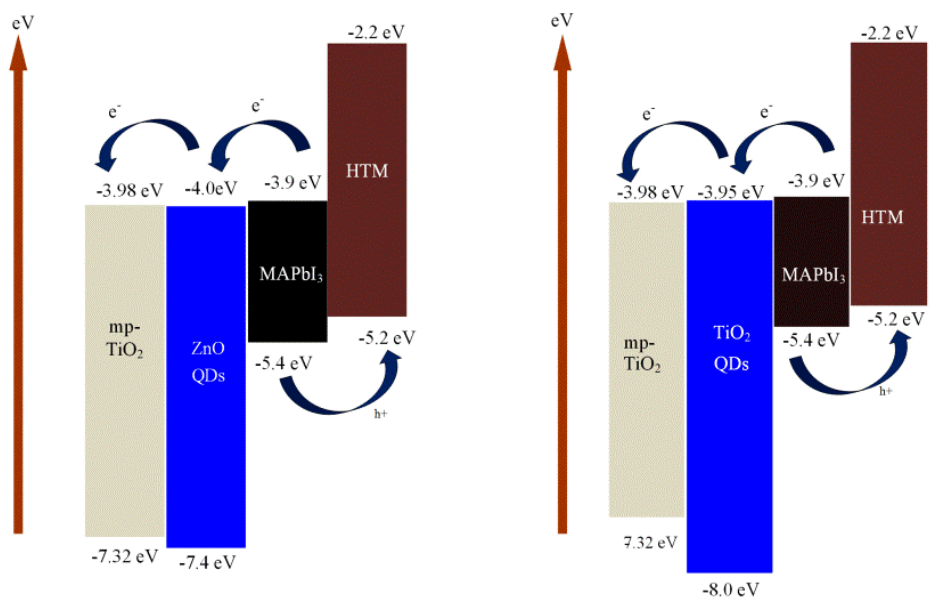

Figure 3. Diagram of energy levels in the ZQDs or TQDs modified device.

To verify whether the QDs can work well in the devices, the surface energies were characterized by UV-vis absorption spectrum and Ultraviolet photoelectron spectroscopy (UPS) (Figure S1). According to the absorption spectra, the band gaps are 3.34, 3.40, $4.05 \mathrm{eV}$ for $\mathrm{mp}-\mathrm{TiO}_{2}$, ZQDs and TQDs, respectively, which are depending on the wavelengths of onset absorption. The valence band maximum 
$\left(E_{V B}\right)$, taken from the UPS, calculated using the expression $E_{V B}=-\left(21.22 \mathrm{eV}-E_{\text {cut-off }}+\right.$ $\mathrm{E}_{\text {fermi }}$ ), are -7.32, -7.4 and $-8.0 \mathrm{eV}$ for $\mathrm{mp}-\mathrm{TiO}_{2}$, ZQDs and TQDs, respectively. The conduction band minimum $\left(\mathrm{E}_{\mathrm{CB}}\right)$ are calculated to be $-3.98,-4.0$ and $-3.95 \mathrm{eV}$ for $\mathrm{mp}-$ $\mathrm{TiO}_{2}, \mathrm{ZQDs}$ and TQDs, respectively, referring to the expression $\mathrm{E}_{\mathrm{CB}}=\mathrm{E}_{\mathrm{VB}}+$ band gap. The band scheme of the mp-TiO $2, Z$ ZDs, TQDs, $\mathrm{MAPbI}_{3}$ and HTM are depicted in Figure 3, from which we can see that both energy levels of ZQDs and TQDs match well with the $\mathrm{mp}-\mathrm{TiO}_{2}$ and perovskite.

a

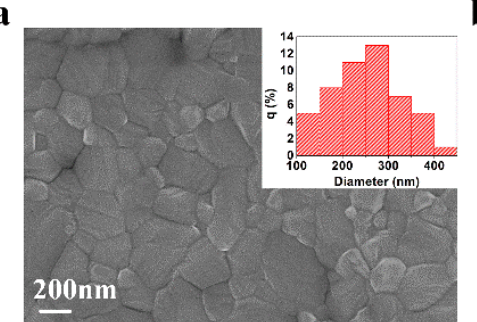

d

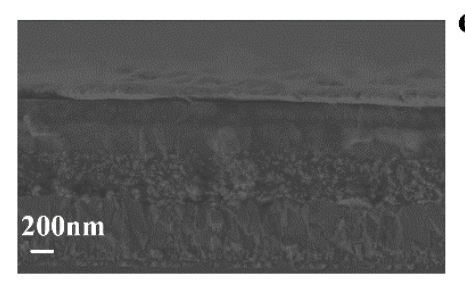

b
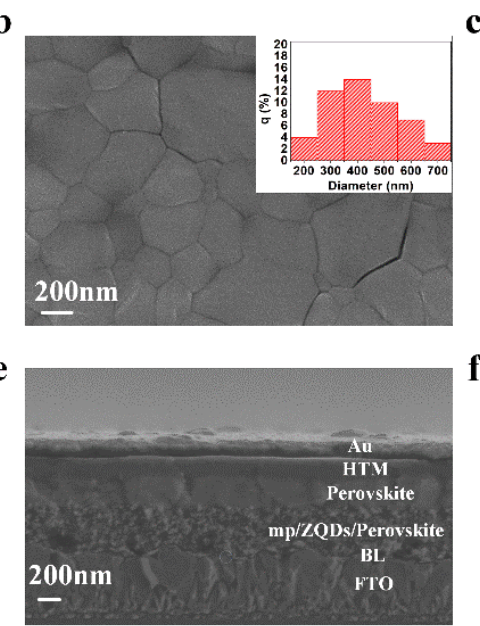

c
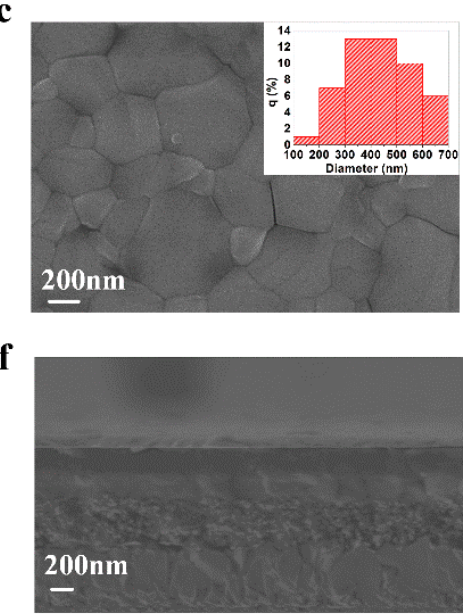

Figure 4. Top-view FESEM images of perovskite crystals grown on (a) the pristine $\mathrm{mp}-\mathrm{TiO}_{2}$, (b) the ZQDs modified mp-TiO ${ }_{2}$ and (c) the TQDs modified $\mathrm{mp}-\mathrm{TiO}_{2}$ film; Cross-sectional SEM images of a complete device based on the (d) PT, (e) PZT and (f) PTT structure. Insets are the grain size distributions of perovskite. The scale bars for all SEM images are $200 \mathrm{~nm}$.

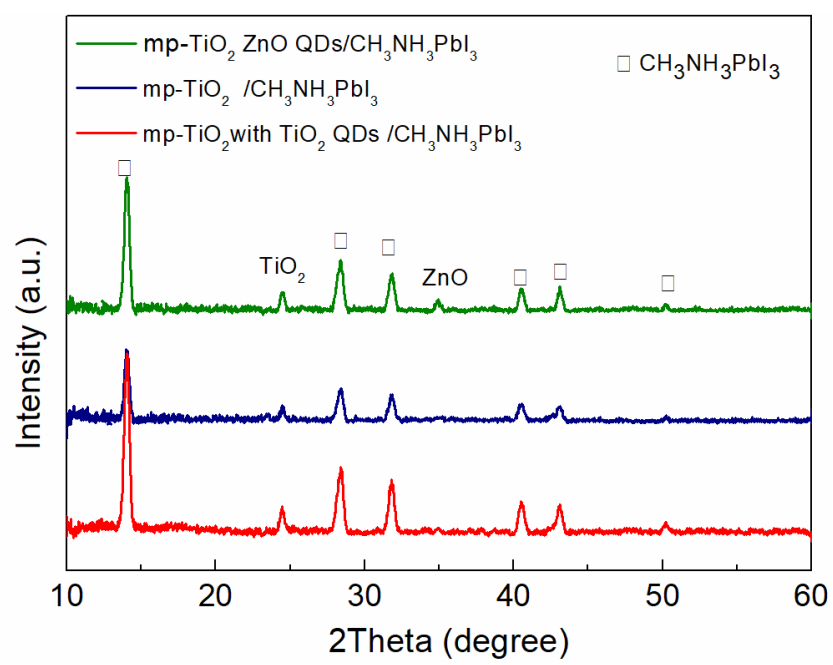

Figure 5. XRD testing results of perovskite films on original $\mathrm{TiO}_{2}$, the $\mathrm{ZQDs}$ treated $\mathrm{TiO}_{2}$ and the 
TQDs treated $\mathrm{TiO}_{2}$ layer.

The $\mathrm{MAPbI}_{3}$ films were formed by spin coating the perovskite precursor solution on the bare or QDs modified mp- $\mathrm{TiO}_{2}$ substrate and then heating at $100^{\circ} \mathrm{C}$ for $2 \mathrm{~min}$. Figure 4,a b, c display the field emission scanning electron microscope (FESEM) topview images of the perovskite films on the bl- $\mathrm{TiO}_{2} / \mathrm{mp}-\mathrm{TiO}_{2}$, bl- $-\mathrm{TiO}_{2} / \mathrm{mp}-\mathrm{TiO}_{2} / \mathrm{ZQDs}$

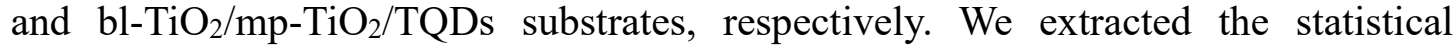
distribution diagrams of perovskite grain size by analyzing the top-view SEM images using the software named nano measurer. From the inset of the SEM images, the grain size is in Gaussian distribution, the average size is $254 \mathrm{~nm}, 420 \mathrm{~nm}$ and $430 \mathrm{~nm}$ for perovskite grown on the bl- $\mathrm{TiO}_{2} / \mathrm{mp}-\mathrm{TiO}_{2}$, bl- $\mathrm{TiO}_{2} / \mathrm{mp}-\mathrm{TiO}_{2} / \mathrm{ZQDs}$ and $\mathrm{bl}-\mathrm{TiO}_{2} / \mathrm{mp}-$ $\mathrm{TiO}_{2} / \mathrm{TQDs}$ substrates, respectively. It shows that the perovskite grain size on the QDs modified substrates is obviously larger than that on the counterpart. The enlargement of perovskite grain sizes may be ascribed to the flowing reasons: First, heterogeneous nucleation is suppressed and less drag force is performed from the QDs modified substrates, yielding increased nucleus spacing and promoted grain boundary migration in grain growth. ${ }^{18}$ Second, the QDs with high surface-to-volume ratio increase the contact area of perovskite/ETL, which is favorable for the formation of a high-quality film. ${ }^{9}$ Third, QDs offer added nucleation sites for perovskite, thus larger grain size can be obtained. ${ }^{12}$ Considering that the grain boundaries and the defect density of the perovskite film can be reduced due to the enlarged grain size, leading to decreased nonradiative recombination and increased charge transport, ${ }^{19,20,21}$ this strategy would be beneficial for achieving high performance optoelectronic devices.

The XRD patterns of perovskite films on different mesoscopic layers are depicted in Figure 5. The stronger peaks of perovskite films coated on the QDs modified mp$\mathrm{TiO}_{2}$ layers indicate higher crystallinity, in line with the results taken from the SEM images above. Therefore, enhanced performances are expected for these QDs modified PSCs.

Then the subsequent HTM and Au electrode were spin coated and thermally evaporated on the perovskite layers, respectively, to form the complete PSC devices. 
The device with bare mp- $\mathrm{TiO}_{2}$ was marked as PT; the devices with ZQDs and TQDs modified mp- $\mathrm{TiO}_{2}$ were marked as PZT and PTT, respectively. Cross-sectional SEM images show in Figure 4d, e, f indicate that the thickness of $\mathrm{MAPbI}_{3}$ over ETLs is not changed significantly through QDs-treatment.
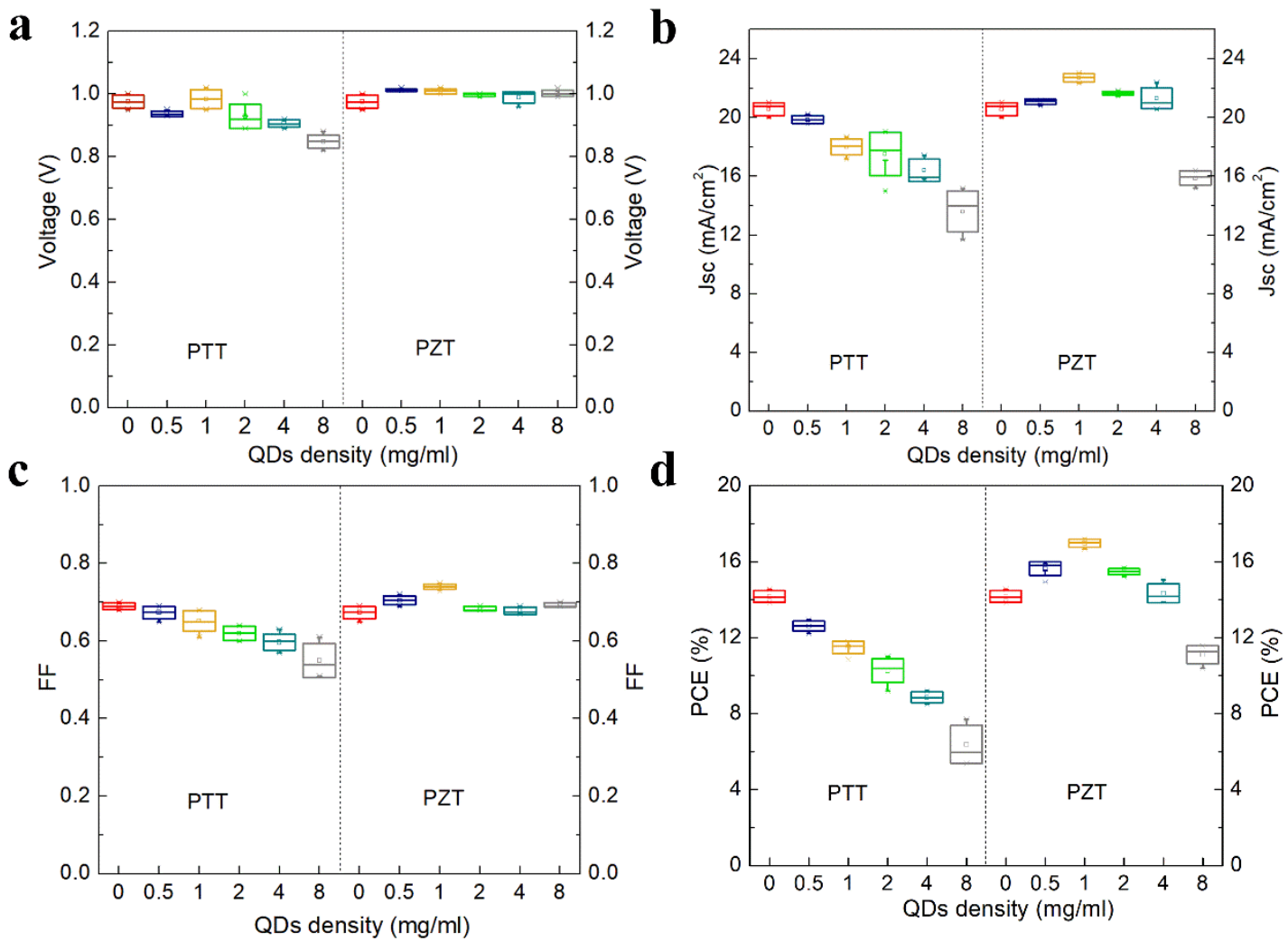

Figure 6. Statistical parameters of $\mathrm{V}_{\mathrm{oc}}(\mathrm{a}), \mathrm{J}_{\mathrm{sc}}(\mathrm{b}), \mathrm{FF}$ (c), and PCE (d) of PSCs based on ETL added with different amounts of ZQDs or TQDs. Each box summarizes the parameter distribution of 12 devices, in which the small square symbol () represents the mean and the line represents the median.

Figure 6 shows the statistical datas of PZT and PTT PSCs modified with different contents $(0,0.5,1,2,4,8 \mathrm{mg} / \mathrm{ml})$ of ZQDs or TQDs. Here the PSCs with $0 \mathrm{mg} / \mathrm{ml}$ QDs are actually PT PSCs. Unexpectedly, as the concentration of QDs increases, the photovoltaic parameters of PZT and PTT PSCs appear different tendencies. Both circuit voltage $\left(\mathrm{V}_{\mathrm{oc}}\right)$ and short circuit current $\left(\mathrm{J}_{\mathrm{sc}}\right)$ of PTT decreased as the TQDs increased, which led to a linear reduction of PCE from $14.17 \%$ to $11.47 \%(1 \mathrm{mg} / \mathrm{ml})$, finally down to $6 \%(8 \mathrm{mg} / \mathrm{ml})$. However, for the PZT PSCs, the $\mathrm{V}_{\mathrm{oc}}$ slightly increased as ZQDs was loaded and remained stable. The average $\mathrm{J}_{\mathrm{sc}}$ first increased from $20.59 \mathrm{~mA} \mathrm{~cm}^{-2}$ to 22.71 
$\mathrm{mA} \mathrm{cm}^{-2}$ after loading $1 \mathrm{mg} / \mathrm{ml}$ ZQDs, and then decreased. With the optimized loading amount of ZQDs, the average PCE of PSCs was enhanced from $14.17 \%$ to $16.96 \%$.
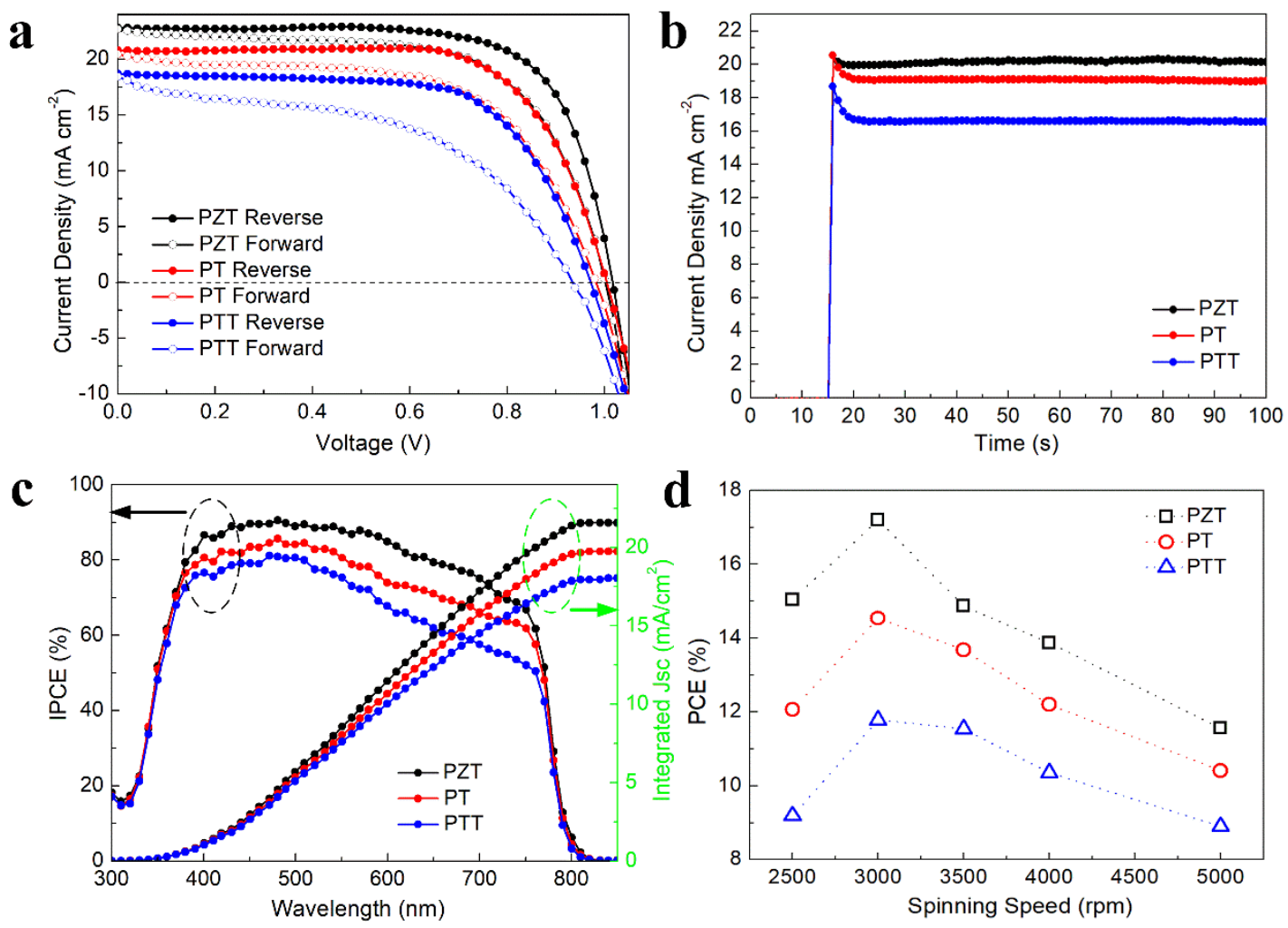

Figure 7. (a) Typical J-V curves of champion PSCs via forward or reverse bias scanning; (b) the relation of output current density at maximum power point with time and (c) IPCE and integrated current data of corresponding devices; (d) The highest PCE for the devices based on PZT, PT and PTT structure when the mesoporous $\mathrm{TiO}_{2}$ layer was operated at different spinning speed. All the measurements were performed using unsealed devices exposure to air with a relative humidity of $\approx 50 \%-65 \%$.

Table 1. Summary of the photovoltaic performance parameters derived from the J-V curves presented in Figure 7a.

\begin{tabular}{llclc}
\hline Sample & $\mathrm{V}_{\mathrm{OC}}[\mathrm{V}]$ & $\mathrm{J}_{\mathrm{SC}}\left[\mathrm{mAcm}^{-2}\right]$ & FF & PCE (\%) \\
\hline PZT (reverse) & 1.02 & 22.79 & 0.74 & 17.20 \\
PZT (forward) & 1.01 & 22.69 & 0.66 & 15.13 \\
PT (reverse) & 1.00 & 20.77 & 0.70 & 14.54 \\
PT (forward) & 0.98 & 20.45 & 0.61 & 12.23
\end{tabular}




$\begin{array}{lllll}\text { PTT (reverse) } & 0.97 & 18.69 & 0.65 & 11.78 \\ \text { PTT (forward) } & 0.93 & 18.43 & 0.50 & 8.57\end{array}$

Figure 7 a shows the current density-voltage $(\mathrm{J}-\mathrm{V})$ curves of the champion PSCs. The photovoltaic parameters are recorded in Table 1. It shows that the champion PZT cell achieved a much higher PCE than that of the PTT cell and reference PT cell. Moreover, the PZT cells showed a smaller J-V hysteresis, which may resulted from the improved electron injection/transport to balance the hole flux at the anode. ${ }^{22}$ Figure $7 \mathrm{~b}$ represented the steady current density at maximum power point as a function of time. The current density increased rapidly and then stabilized at 20.26, 19.13 and $16.66 \mathrm{~mA}$ $\mathrm{cm}^{-2}$ for PZT, PT and PTT cells, respectively. Incident photon-to-current conversion efficiency (IPCE) results in Figure 7c showed that the PZT cell exhibited higher light response capacity over the entire wavelength range compared to the PT and PTT cells, which corresponded to the accelerated electron extract. Meanwhile, the integrated current density of the PZT, PT and PTT device was 21.6, 19.82 and $18.05 \mathrm{~mA} \mathrm{~cm}^{-2}$ respectively, which was consistent with the $\mathrm{J}_{\mathrm{SC}}$ extracted from their $\mathrm{J}-\mathrm{V}$ curves. Moreover, the effect of $\mathrm{mp}-\mathrm{TiO}_{2}$ layer's thickness on the device efficiency was investigated. The thickness of $\mathrm{mp}-\mathrm{TiO}_{2}$ layers was controlled by changing the spincoating speed from 2500 to $5000 \mathrm{rpm}$ while keeping otherwise identical conditions. We found that the optimal spin-coating speed was $3000 \mathrm{rpm}$ and the highest PCE values of the devices followed the sequence as PCE $(\mathrm{PTT})<\mathrm{PCE}(\mathrm{PT})<\mathrm{PCE}(\mathrm{PZT})$ as before (Figure 7d).

Seen from Table 1 , the value of $\mathrm{V}_{\mathrm{oc}}$ was slightly changed, the change of PCE was mainly caused by $\mathrm{J}_{\mathrm{sc}}$. As a preliminary, we carried out the optical absorption studies. For PSCs, the strong capacity of light absorption plays an important role in high device performance. Seen from the results in Figure 8, the $\mathrm{MAPbI}_{3}$ films exhibited a wide light absorbance range from the UV region to $800 \mathrm{~nm}$. The $\mathrm{MAPbI}_{3}$ film grown on the ZQDs modified $\mathrm{mp}-\mathrm{TiO}_{2}$ film (black curve) showed a considerable enhancement in UVvisible absorbance than the reference one (red curve), while the TQDs modified film (blue curve) showed a weakened light absorption. 


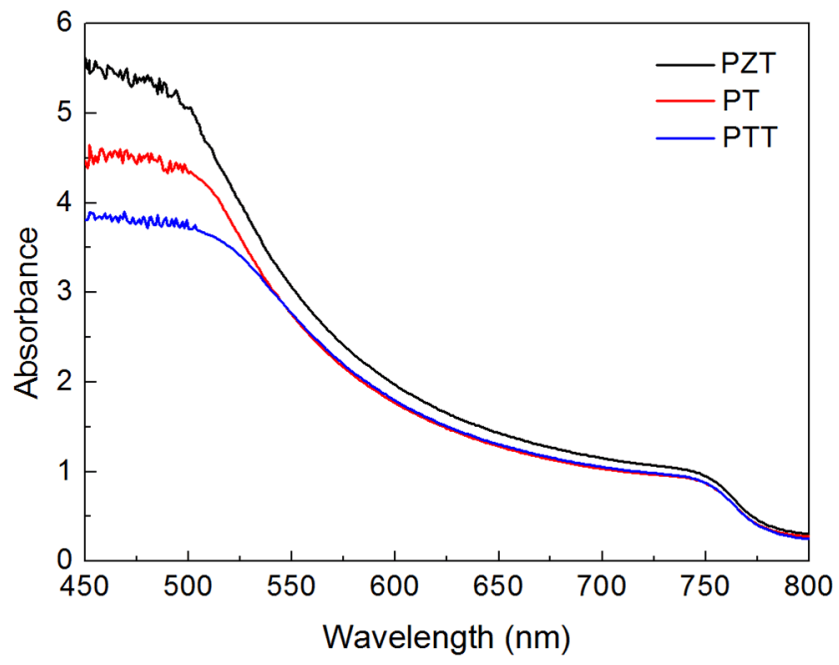

Figure 8. UV/vis absorbance spectra of PZT, PT and PTT film.

Light absorption is strongly affected by the crystallinity, loading amount and surface coverage. The loading amount is decided by the thickness of capping layer and the infiltration of $\mathrm{MAPbI}_{3}$ perovskite in $\mathrm{mp}-\mathrm{TiO}_{2}$ layer, which is determined by the morphology of the mesoporous layer. ${ }^{23,24}$ Though both top and cross-sectional SEM images of PZT and PTT showed that the crystallinity and thickness of capping layer of perovskite looked the same, the infiltration content was still unclear. Thus, a deep insight into the surface appearance of the pores before and after modification was performed subsequently. We checked the atomic force microscopy (AFM) micrographs of the bare $\mathrm{mp}-\mathrm{TiO}_{2}$ (a), ZQDs modified (b) and TQDs modified ones (c) as presented in Figure 9. It was observed that the mesoscopic $\mathrm{TiO}_{2}$ particles were approximately spherical shape, randomly arranged and accompanied by the formation of a lot of large void spaces; the ZQDs (small bright spots) were extensively distributed on the surface of the mesoporous layer, resulting in less and smaller pores. However, the TQDs gathered at the surface of $\mathrm{mp}-\mathrm{TiO}_{2}$ particles and thus blocked most of the pores, mainly ascribed to the identical component between TQDs and the mp- $\mathrm{TiO}_{2}$. 
a

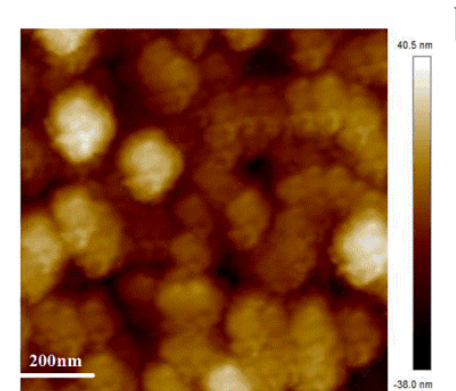

d

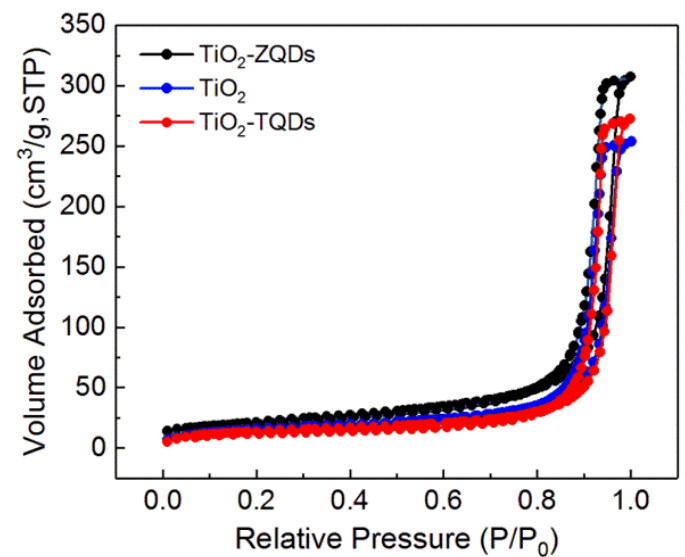

b
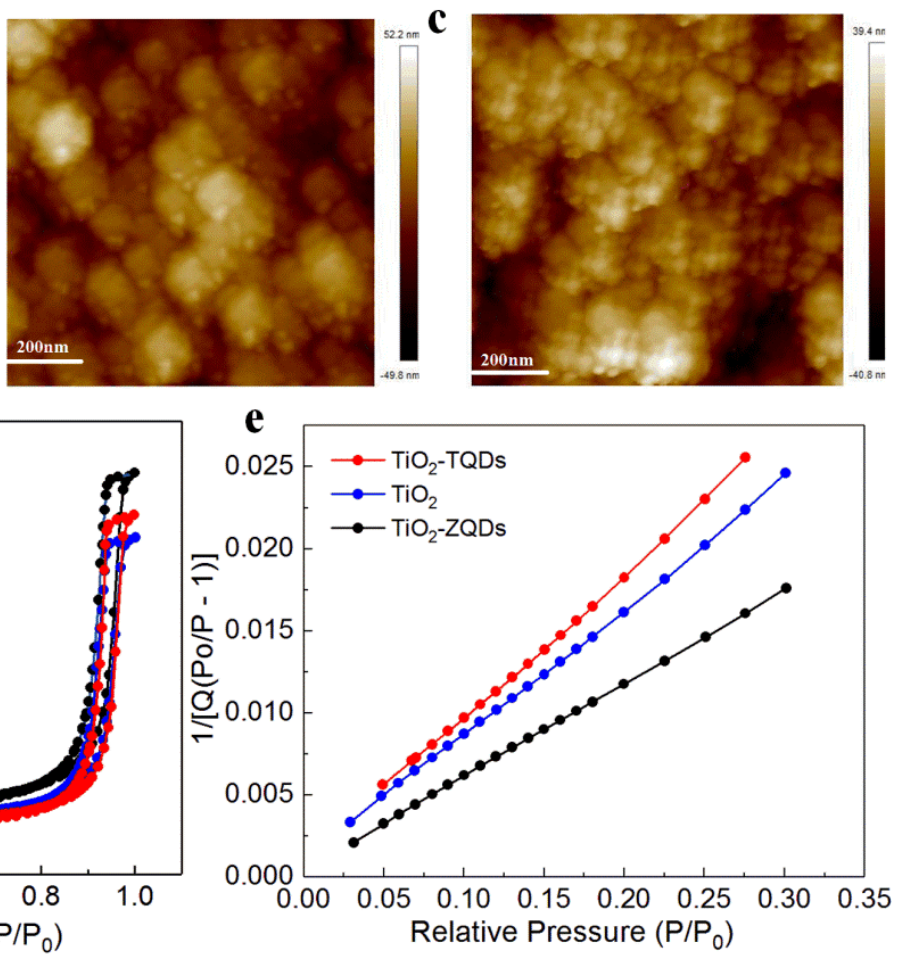

Figure 9. Top-view AFM images of (a) the pristine $\mathrm{TiO}_{2}$, (b) the $\mathrm{ZQDs}$ modified $\mathrm{TiO}_{2}$ and (c) the TQDs modified $\mathrm{TiO}_{2}$ film; (d) $\mathrm{N}_{2}$ adsorption-desorption isotherms and (e) BET surface area plot of the three kinds of $\mathrm{mp}-\mathrm{TiO}_{2}$. The AFM image sizes are all $1 \times 1 \mu \mathrm{m}$.

The enhanced light absorption can help to explain the higher photocurrent and higher light harvesting efficiency in $\mathrm{J}-\mathrm{V}$ curves above. ${ }^{25}$ As no visible morphological difference was found between ZQDs-treatment and TQDs-treatment in the SEM top and cross-sectional images, the decreased light absorption for PTT film in Figure 8 (blue curve) may be ascribed to the reduced perovskite amount within the mesoporous layer caused by the blockage of pores.

Therefore, BET measurement was performed to investigate the pore volume and the specific surface area of the three samples. Figure 9d, e shows the $\mathrm{N}_{2}$ adsorption-desorption isotherms and the corresponding BET surface area plots of mp $\mathrm{TiO}_{2}, \mathrm{ZQDs}-\mathrm{mp} \mathrm{TiO}_{2}$ and TQDs-mp $\mathrm{TiO}_{2}$. The type IV (Brunauer -Deming DemingTeller (BDDT) classification) isotherms for the above three samples indicated that mesopores were present. The type H3 hysteresis loops demonstrated the formation of slit-like pores, which were formed from the aggregation of the nanoparticles. ${ }^{26}$ As the 
pore volume directly determines the amount of $\mathrm{MAPbI}_{3}$ within the mesoporous layer, the sharply decreased pore volume for the TQDs treated film will consequentially lead to the decreased fillers. Furthermore, the increased specific surface area of the oxides modified with ZQDs contributed to effective contact between $\mathrm{MAPbI}_{3}$ and ETL, which is a significant player in the improved photovoltaic performance (Table 2).

Table 2. Summary of pore volume and BET surface area of $\mathrm{mp} \mathrm{TiO} 2, \mathrm{ZQDs}-\mathrm{mp} \mathrm{TiO}_{2}$ and TQDs-mp $\mathrm{TiO}_{2}$.

\begin{tabular}{|c|c|c|}
\hline Sample & Pore volume $\left(\mathrm{cm}^{3} / \mathrm{g}\right)$ & BET surface area $\left(\mathrm{m}^{2} / \mathrm{g}\right)$ \\
\hline $\mathrm{mp} \mathrm{TiO}_{2}$ & 0.475 & 55.962 \\
\hline ZQDs-mp $\mathrm{TiO}_{2}$ & 0.422 & 76.159 \\
\hline TQDs-mp $\mathrm{TiO}_{2}$ & 0.393 & 49.372 \\
\hline
\end{tabular}
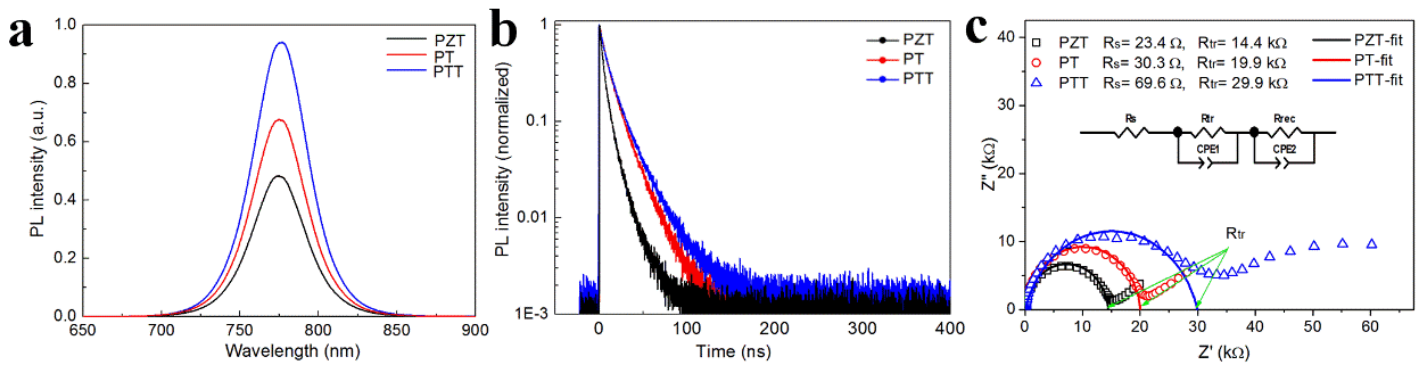

Figure 10. (a) PL spectra and (b) TRPL decay curves of the PT, PZT and PTT films; (c) the test Nyquist plots and the fitting curves of devices measured under ambient conditions in dark with a bias of $700 \mathrm{mV}$. The fitting curve is obtained according to the equivalent circuit in the inset.

In addition to the enhanced light absorption, we suspected that the ZQDs-treated $\mathrm{mp}-\mathrm{TiO}_{2}$ could improve the charge separation and extraction due to the increased contact interfaces. So, we conducted the steady-state photoluminescence (PL) and timeresolved PL (TRPL) measurements on the $\mathrm{MAPbI}_{3}$ films with different mesoporous layer, as shown in Figure 10. All samples exhibited a PL peak at $770 \mathrm{~nm}$ (excitation wavelength $532 \mathrm{~nm}$ ) derived from the perovskite, which was in agreement with the band edge emission from $\mathrm{MAPbI}_{3}$ reported before. ${ }^{27}$ Nevertheless, there existed great difference for the perovskite PL intensity among them. The PZT film exhibited a much 
lower PL intensity than PT film, suggesting a less radiative recombination which may resulted from the increased electron extraction from $\mathrm{MAPbI}_{3}$ to the electrode. Instead, the PTT film showed a much stronger PL intensity. To further study the difference of the behavior of excited electrons in the perovskite layer, TRPL measurements were performed. As displayed in Figure 10b, the average lifetimes of PT, PZT and PTT film were $21 \mathrm{~ns}, 14 \mathrm{~ns}$ and $28 \mathrm{~ns}$, respectively, which were obtained by fitting the decay curves with a double-exponential function. ${ }^{28}$ That is, the PZT sample exhibited the fasted PL quenching rate, which meant faster charge-carrier extraction across interface. ${ }^{29,}{ }^{30}$ These results confirmed that the electron extraction was significantly speeded up by introducing ZQDs and the result was exactly opposite after replacing them with TQDs.

To further confirm the charge transfer at the perovskite / ETL interface, Nyquist plots in Figure 10c were recorded in dark over a frequency of $100 \mathrm{mHz}$ to $1 \mathrm{MHz}$ under an applied bias of $0.7 \mathrm{~V}$. Seen from the Nyquist plots, a semicircle and an incomplete semicircle could be distinguished, which were corresponding to the charge transfer resistance $\left(R_{t r}\right)$ and the recombination resistance $\left(R_{\text {rec }}\right)$, respectively. ${ }^{31}$ Here we mainly focus on the $\mathrm{R}_{\mathrm{tr}}$ by fitting the first semicircle at high frequency region using the equivalent circuit model (inset). The obviously different fitted $\mathrm{R}_{\mathrm{tr}}$ values of PZT, PT and PTT were $14.4 \mathrm{k} \Omega, 19.9 \mathrm{k} \Omega$ and $29.9 \mathrm{k} \Omega$, respectively. The smallest $\mathrm{R}_{\mathrm{tr}}$ value of PZT indicated the most efficient charge transfer at the interface of ZQDs treated mp$\mathrm{TiO}_{2}$ and $\mathrm{MAPbI}_{3}$, resulting in the highest $\mathrm{J}_{\mathrm{sc}}$ of PSCs, in accordance with the results of PL experiments discussed above. Besides, the series resistances (Rs) of devices, originated from the external contacts, were $23.4 \Omega, 30.3 \Omega$ and $69.6 \Omega$ for PZT, PT and PTT, respectively. The decrease of Rs also has a positive effect on FF, ${ }^{32}$ leading to a corresponding increase of PCE for PZT PSCs.

\section{Conclusions}

In short, we designed an improved mesoscopic PSC by inserting ZQDs, treated by a simple solution method, between perovskite and the $\mathrm{mp}-\mathrm{TiO}_{2}$ layer. With optimized 
ZQDs modification contents, the PSC could achieve a greatly improvement in PCE, from $14.54 \%$ to $17.20 \%$, due to the remarkable increase in $\mathrm{J}_{\mathrm{sc}}$. This result should be attributed to the enhanced light absorption of perovskite film, improved electron extraction capability and well-matched energy levers. After replacing ZQDs with TQDs who have similar size with ZQDs and the same component with $\mathrm{mp}-\mathrm{TiO}_{2}$, the device performance was deteriorated owing to the sharply decreased specific surface area because of the aggregation of TQDs. The results provide us an efficient and facile way to speed up the electron transport from the perovskite absorber to the current collector and to improve the photovoltaic performance of mesoscopic PSCs.

\section{Conflicts of interest}

There is no conflict to declare.

\section{Acknowledgements}

This work is financially supported by the Talent Fund of Hubei University of Technology (Grant No. BSQD2020107), National Key R\&D Program of China (Grant No. 2017YFB0406405), Science and Technology Research Project of Education Department of Hubei Province (Q20201402), they are greatly acknowledged. We also acknowledge the assistance from the Analytical and Testing Center of HUST.

\section{Appendix A. Supplementary data}

Supplementary data to this article is available.

\section{References}

[1] Kojima A, Teshima K, Shirai Y, et al. O-rganometal halide perovskites as visiblelight sensitizers for photovoltaic cells. J Am Chem Soc 2009, 131:6050-6051.

[2] Zhang T, Wu J, Zhang P, et al. High Speed and stable solution-processed triple cation perovskite photodetectors. Adv Opt Mater 2018, 6:1701341.

[3] NREL, https://www.nrel.gov/pv/assets/pdfs/ best-research-cell-efficiencies. 
20200925. pdf (accessed: September 2020).

[4] Gratzel M. The light and shade of perovskite solar cells. Nat Mater 2014, 13:838842.

[5] Guillén E, Ramos FJ, Anta JA, et al. Elucidating Transport-Recombination Mechanisms in Perovskite Solar Cells by Small-Perturbation Techniques. $J$ Phy Chem C 2014,118:22913-22922.

[6] Heo JH, You MS, Chang $\mathrm{MH}$, et al. Hysteresis-less mesoscopic $\mathrm{CH}_{3} \mathrm{NH}_{3} \mathrm{PbI}_{3}$ perovskite hybrid solar cells by introduction of Li-treated $\mathrm{TiO}_{2}$ electrode. Nano Energy 2015,15:530-539.

[7] Kim HS, Lee JW, Yantara N, et al. High efficiency solid-state sensitized solar cellbased on submicrometer rutile $\mathrm{TiO}_{2}$ nanorod and $\mathrm{CH}_{3} \mathrm{NH}_{3} \mathrm{PbI}_{3}$ perovskite sensitizer. Nano Lett 2013, 13:2412-2417.

[8] Son D-Y, Im J-H, Kim H-S, et al. 11\% Efficient Perovskite Solar Cell Based on ZnO Nanorods: An Effective Charge Collection System. J Phy Chem C 2014, 118: $16567-16573$.

[9] Xiong Y, Liu Y, Lan K, et al. Fully printable hole-conductor-free mesoscopic perovskite solar cells based on mesoporous anatase single crystals. New J Chem 2018, 42:2669-2674.

[10] Garcia VJ, Pelicano CM, Yanagi H. Low temperature-processed ZnO nanorods$\mathrm{TiO}_{2}$ nanoparticles composite as electron transporting layer for perovskite solar cells. Thin Solid Films 2018, 662:70-75.

[11] Seo JY, Uchida R, Kim HS, et al. Boosting the efficiency of perovskite solar cells with $\mathrm{CsBr}$-modified mesoporous $\mathrm{TiO}_{2}$ beads as electron-selective contact. $A d v$ Funct Mater 2018, 28:1705763.

[12]Chen W, Li K, Wang Y, et al. Black Phosphorus Quantum Dots for Hole Extraction of Typical Planar Hybrid Perovskite Solar Cells. J Phys Chem Lett 2017, 8:591598.

[13]Zeng X, Zhou T, Leng C, et al. Performance improvement of perovskite solar cells by employing a CdSe quantum dot/PCBM composite as an electron transport layer. 
J Mater Chem A 2017, 5:17499-17505.

[14]Ryu J, Lee JW, Yu H, et al. Size effects of a graphene quantum dot modifiedblocking $\mathrm{TiO}_{2}$ layer for efficient planar perovskite solar cells. J Mater Chem A 2017, 5:16834-16842.

[15]Li H, Shi W, Huang W, et al. Carbon Quantum Dots/TiO x Electron Transport Layer Boosts Efficiency of Planar Heterojunction Perovskite Solar Cells to 19\%. Nano Lett 2017, 17:2328-2335.

[16]Zhang Q, Dandeneau CS, Zhou X, et al. ZnO Nanostructures for Dye-Sensitized Solar Cells. Adv Mater 2009, 21:4087-4108.

[17]Park K, Zhang Q, Garcia BB, et al. Effect of an Ultrathin $\mathrm{TiO}_{2}$ Layer Coated on Submicrometer-Sized $\mathrm{ZnO}$ Nanocrystallite Aggregates by Atomic Layer Deposition on the Performance of Dye-Sensitized Solar Cells. Adv Mater 2010, 22:2329-2332.

[18]Bi C, Wang Q, Shao Y, et al. Non-wetting surface-driven high-aspect-ratio crystalline grain growth for efficient hybrid perovskite solar cells. Nat Commun 2015, 6:7747.

[19]Liu D, Wu L, Li C, et al. Controlling $\mathrm{CH}_{3} \mathrm{NH}_{3} \mathrm{PbI}_{3-\mathrm{x}} \mathrm{Cl}$ x Film Morphology with Two-Step Annealing Method for Efficient Hybrid Perovskite Solar Cells. ACS Appl Mater Inter 2015, 7:16330-16337.

[20]Zhou H, Chen Q, Li G, et al. Interface engineering of highly efficient perovskite solar cells. Science 2014, 345:542-546.

[21] Wang Y, Wu J, Zhang P, et al. Stitching triple cation perovskite by a mixed antisolvent process for high performance perovskite solar cells. Nano Energy 2017, 39:616-625.

[22] Yang D, Zhou X, Yang R, et al. Surface optimization to eliminate hysteresis for record efficiency planar perovskite solar cells. Energy Environ Sci 2016, 9:30713078 .

[23]Leijtens T, Lauber B, Eperon GE, et al. The importance of perovskite pore filling in organometal mixed halide sensitized $\mathrm{TiO}_{2}$-based solar cells. J Phy Chem Lett 
2014, 5:1096-1102.

[24] Yin J, Cao J, He X, et al. Improved stability of perovskite solar cells in ambient air by controlling the mesoporous layer. J Mater Chem A 2015, 3:16860-16866.

[25]Chen Y, Chen T, Dai L. Layer-by-Layer Growth of $\mathrm{CH}_{3} \mathrm{NH}_{3} \mathrm{PbI}_{3-\mathrm{x}} \mathrm{Cl}_{\mathrm{x}}$ for Highly Efficient Planar Heterojunction Perovskite Solar Cells. Adv Mater 2015, 27:10531059.

[26] Wang G, Zhu X, Yu J. Bilayer hollow/spindle-like anatase TiO2 photoanode for high efficiency dye-sensitized solar cells. J Power Sources 2015, 278:344-351.

[27]Xie Y, Shao F, Wang Y, et al. Enhanced performance of perovskite $\mathrm{CH}_{3} \mathrm{NH}_{3} \mathrm{PbI}_{3}$ solar cell by using $\mathrm{CH}_{3} \mathrm{NH}_{3} \mathrm{I}$ as additive in sequential deposition. ACS Appl Mater Inter 2015, 7:12937-12942.

[28] Wang J, Cao R, Da P, et al. Purcell effect in an organic-inorganic halide perovskite semiconductor microcavity system. Appl Phy Lett 2016, 108:022103.

[29]Zheng $\mathrm{X}$, Wei Z, Chen $\mathrm{H}$, et al. Designing nanobowl arrays of mesoporous $\mathrm{TiO}_{2}$ as an alternative electron transporting layer for carbon cathode-based perovskite solar cells. Nanoscale 2016, 8:6393-6402.

[30]Li S, Zhang P, Wang Y, et al. Interface engineering of high efficiency perovskite solar cells based on $\mathrm{ZnO}$ nanorods using atomic layer deposition. Nano Res 2017, 10:1092-1103.

[31]Christians JA, Fung RC, Kamat PV. An inorganic hole conductor for organo-lead halide perovskite solar cells. Improved hole conductivity with copper iodide. $J \mathrm{Am}$ Chem Soc 2013, 136:758-764.

[32]Juarez-Perez EJ, Wußler M, Fabregat-Santiago F, et al. Role of the selective contacts in the performance of lead halide perovskite solar cells. J Phy Chem Lett 2014, 5:680-685. 
Figures
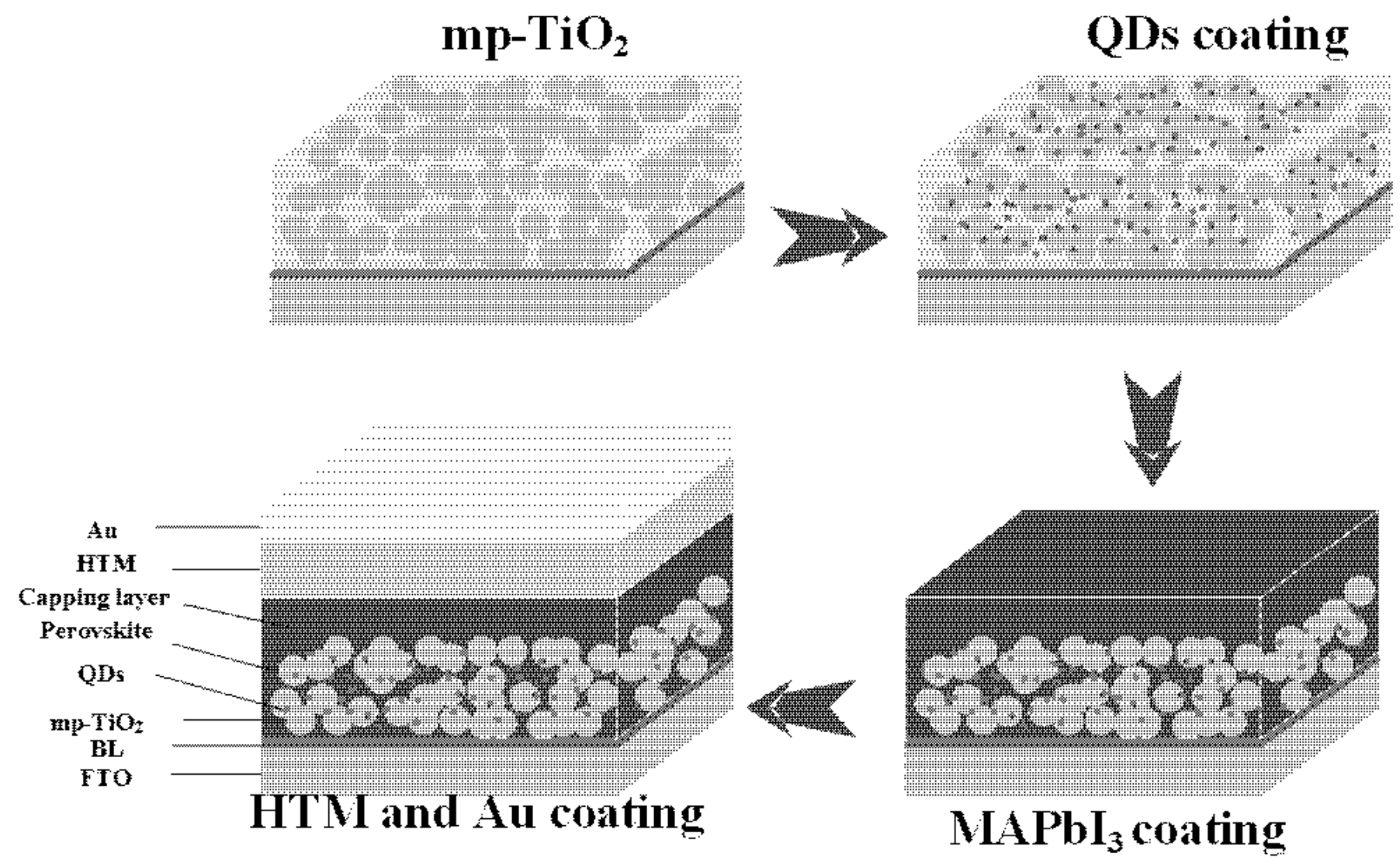

Figure 1

Fabrication process of QDs modified PSCs. 

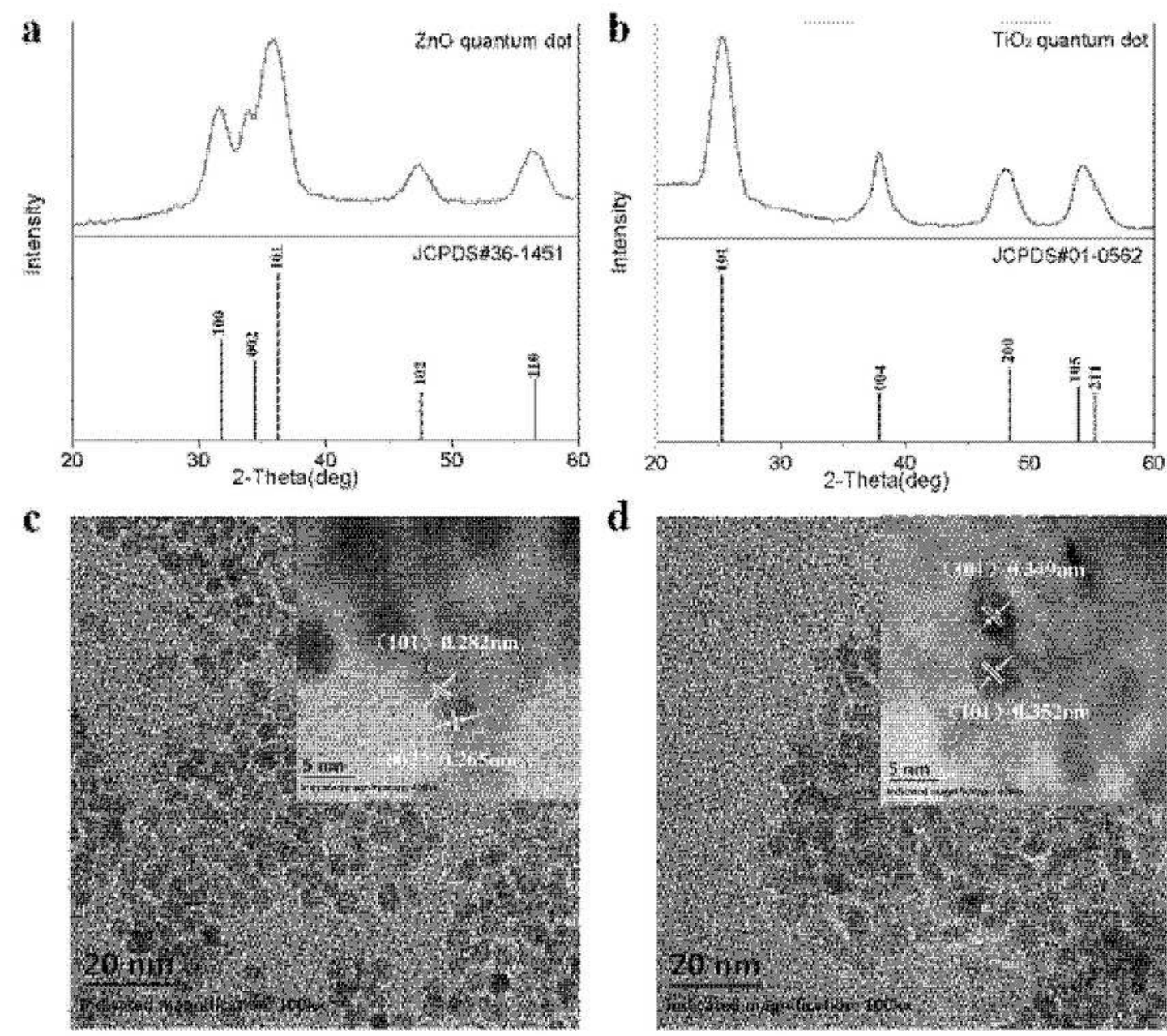

d

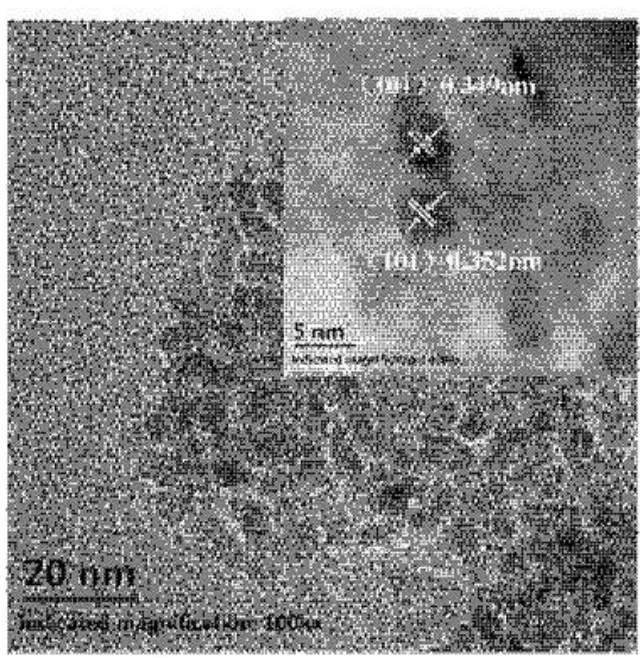

$\mathbf{e}$
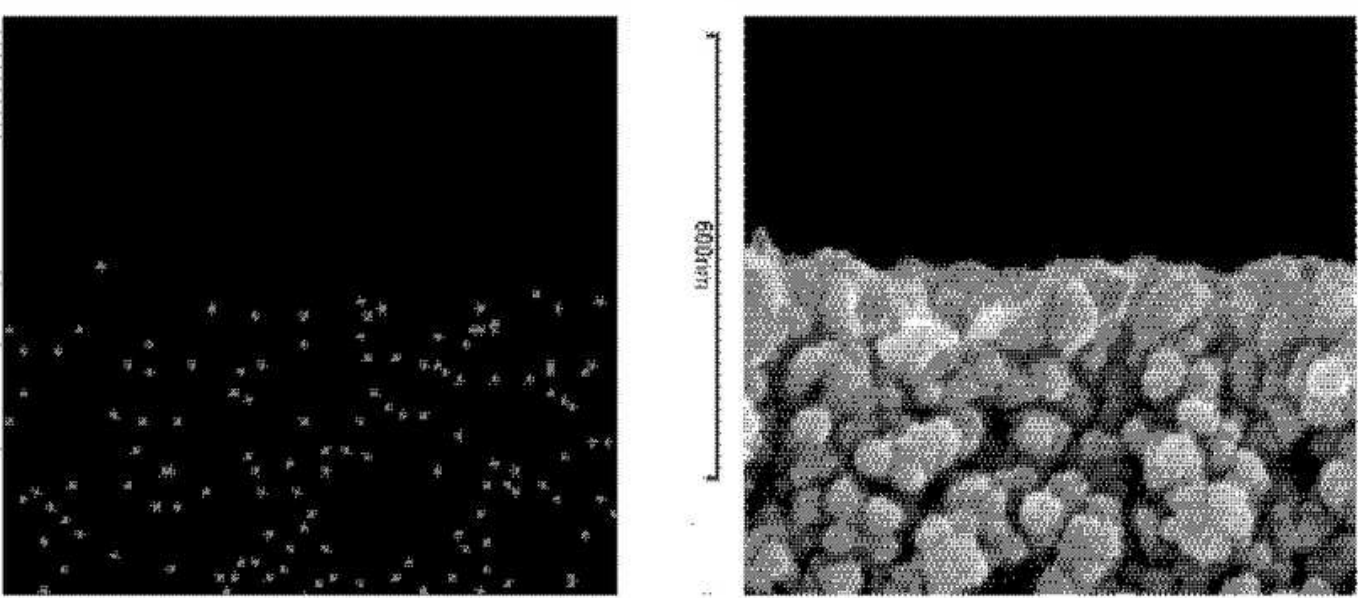

Figure 2

XRD testing results of (a) ZQDs and (b) TQDs; TEM and HRTEM (inset) image of (c) ZQDs and (d) TQDs; (e) distribution of $\mathrm{Zn}$ in ZQDs/mp-TiO2 sample obtained from the cross section-scan analysis of EDS mapping images and the corresponding cross section SEM image. 

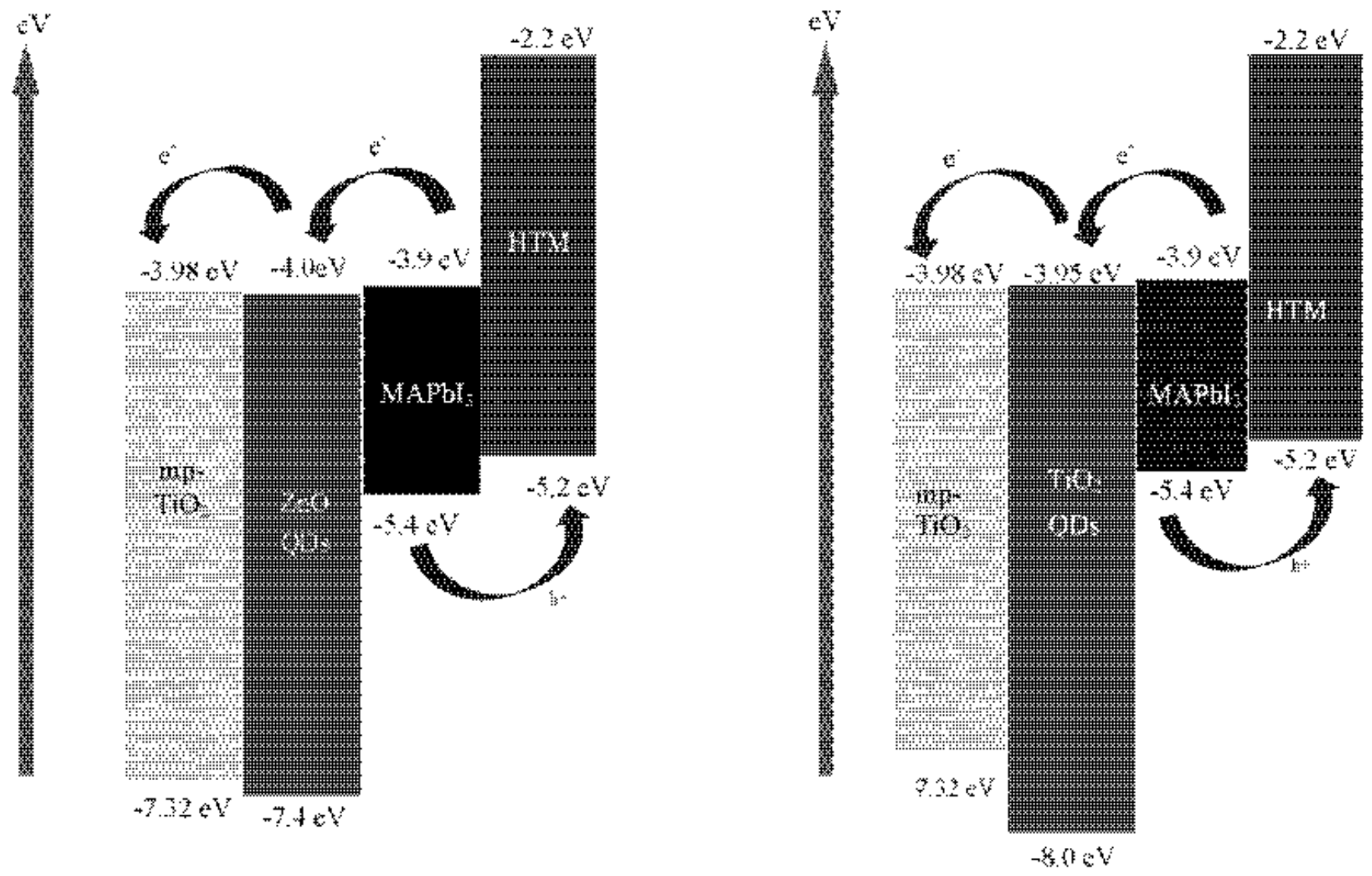

Figure 3

Diagram of energy levels in the ZQDs or TQDs modified device.

a

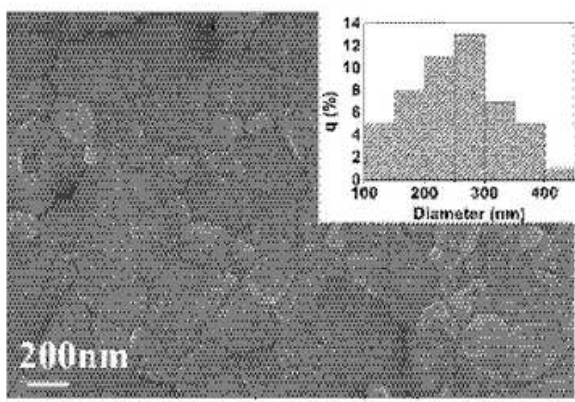

d

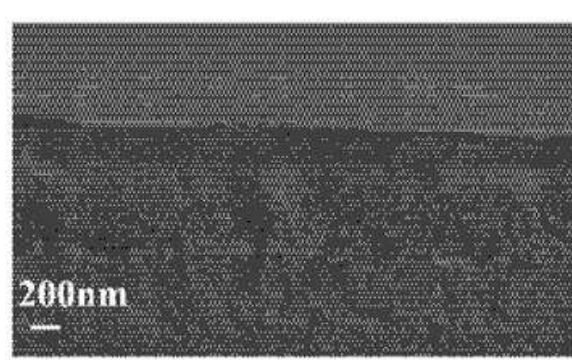

b

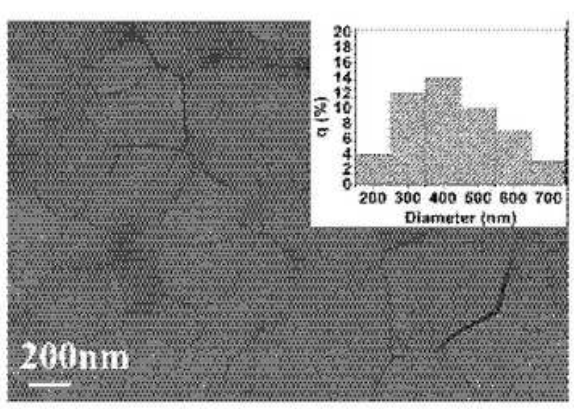

e

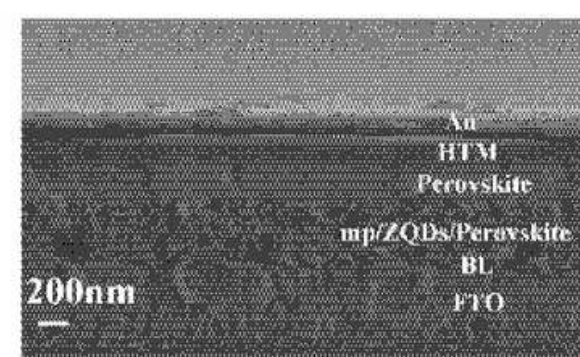

c

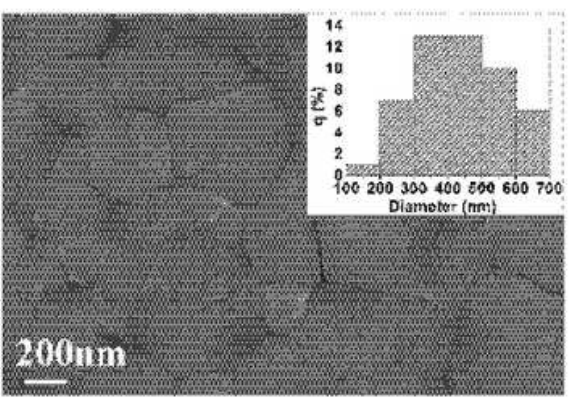

f

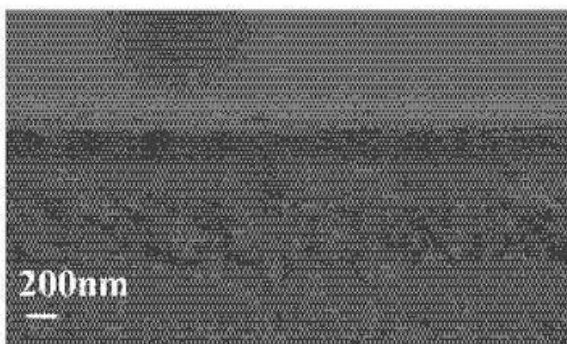

Figure 4 
Top-view FESEM images of perovskite crystals grown on (a) the pristine mp-TiO2, (b) the ZQDs modified $\mathrm{mp}-\mathrm{TiO} 2$ and (c) the TQDs modified mp-TiO2 film; Cross-sectional SEM images of a complete device based on the (d) PT, (e) PZT and (f) PTT structure. Insets are the grain size distributions of perovskite. The scale bars for all SEM images are $200 \mathrm{~nm}$.

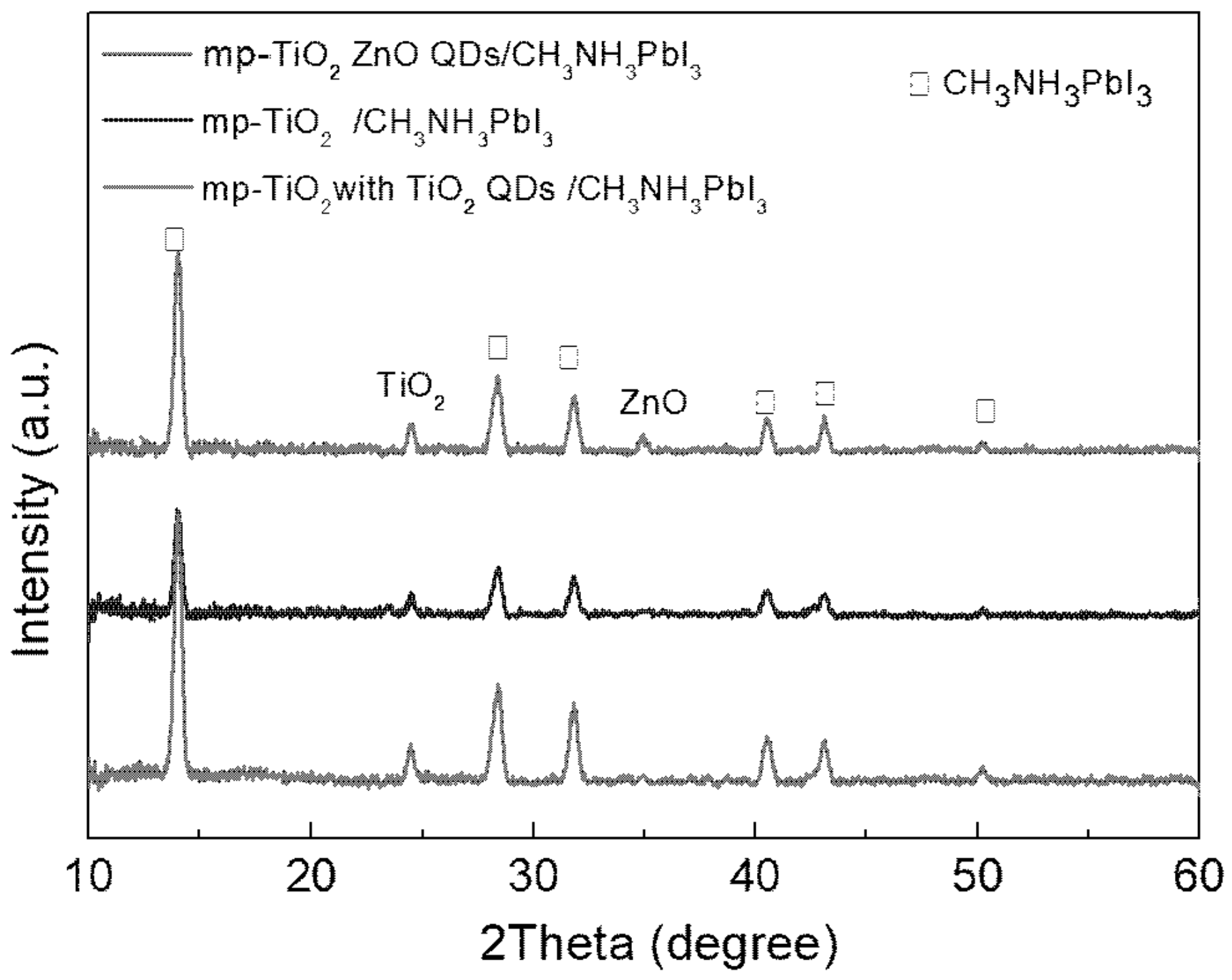

Figure 5

XRD testing results of perovskite films on original TiO2, the ZQDs treated TiO2 and the TQDs treated TiO2 layer. 

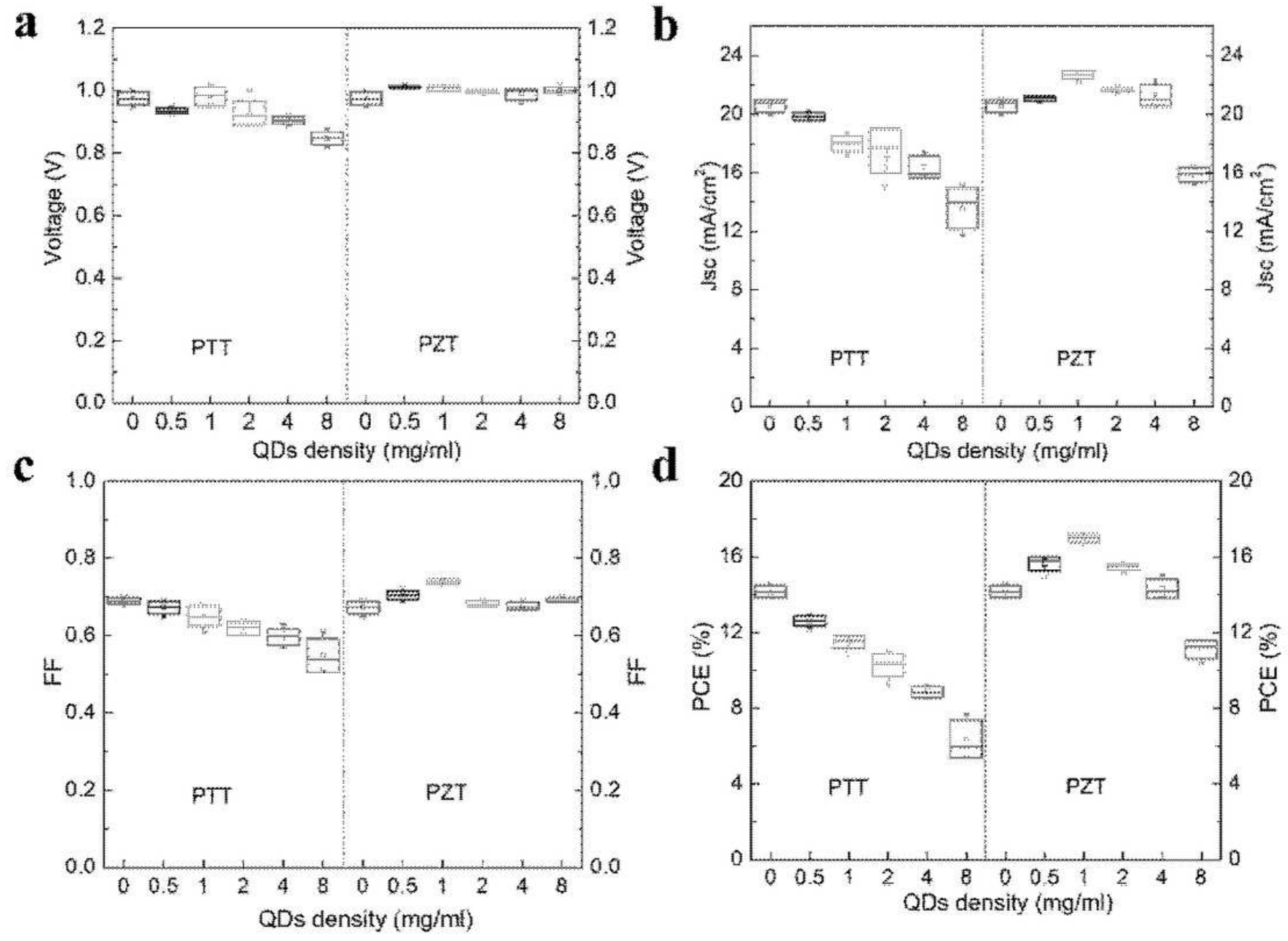

Figure 6

Statistical parameters of Voc (a), Jsc (b), FF (c), and PCE (d) of PSCs based on ETL added with different amounts of ZQDs or TQDs. Each box summarizes the parameter distribution of 12 devices, in which the small square symbol $(\mathbb{\nabla})$ represents the mean and the line represents the median. 
$\mathbf{a}$

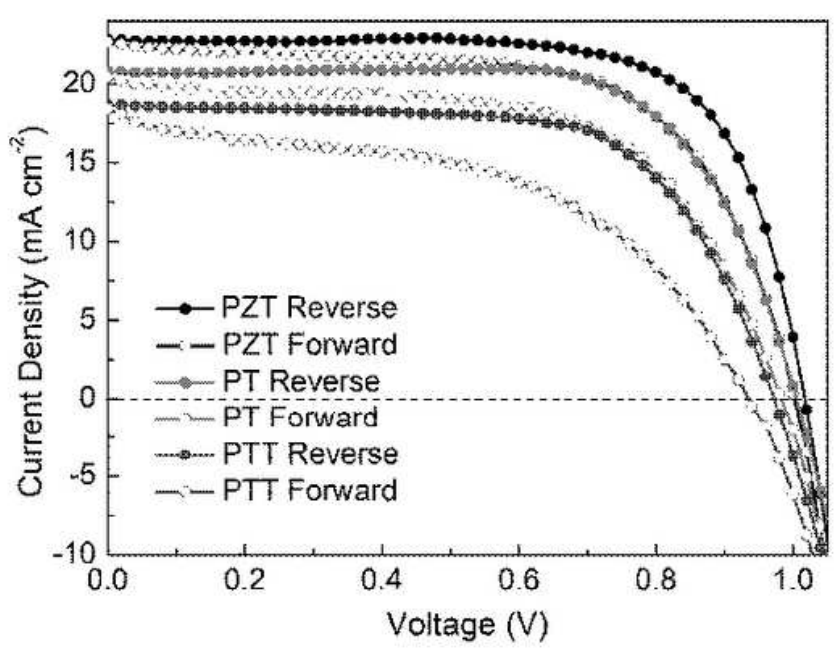

c

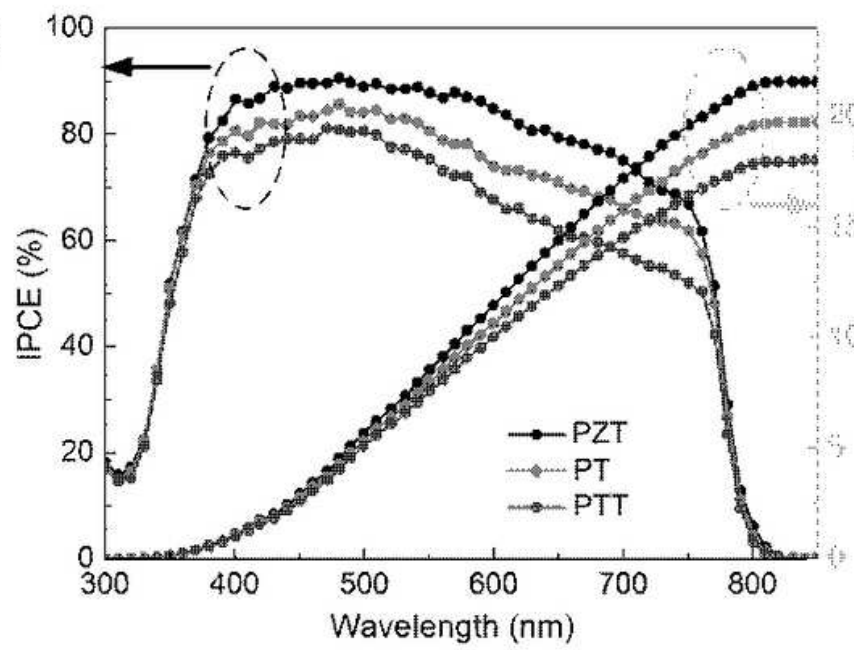

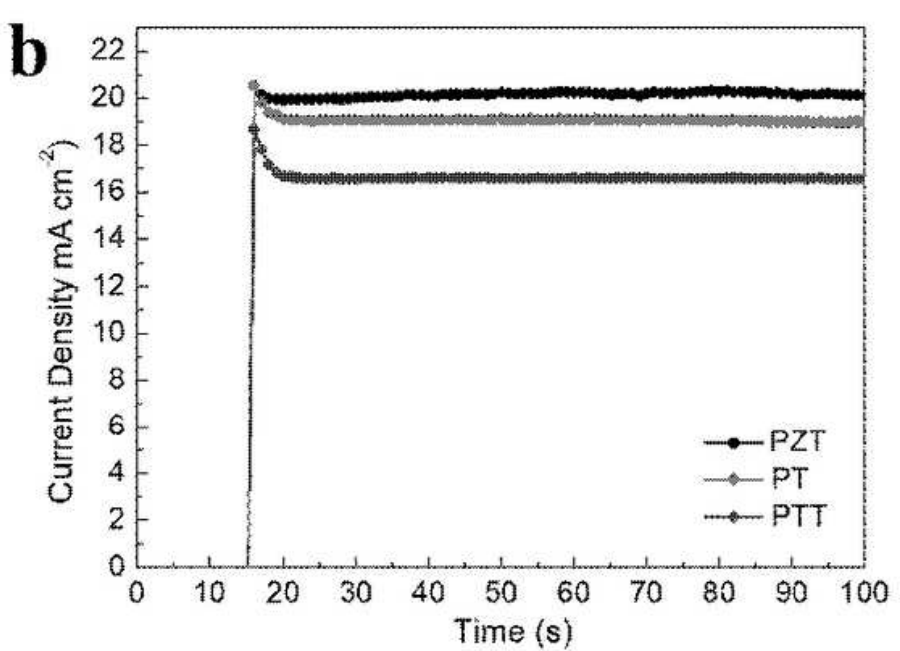

d

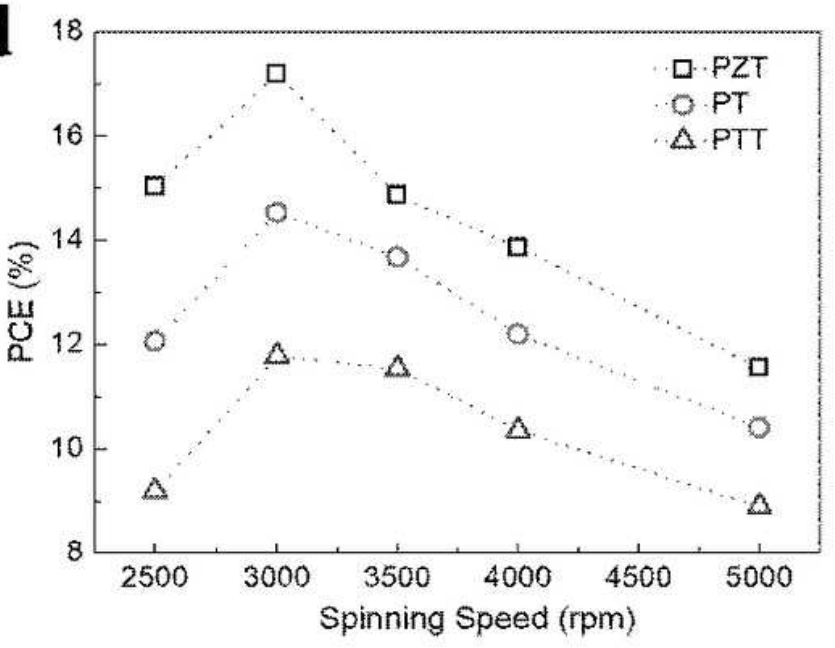

Figure 7

(a) Typical J-V curves of champion PSCs via forward or reverse bias scanning; (b) the relation of output current density at maximum power point with time and (c) IPCE and integrated current data of corresponding devices; (d) The highest PCE for the devices based on PZT, PT and PTT structure when the mesoporous TiO2 layer was operated at different spinning speed. All the measurements were performed using unsealed devices exposure to air with a relative humidity of $\approx 50 \%-65 \%$. 


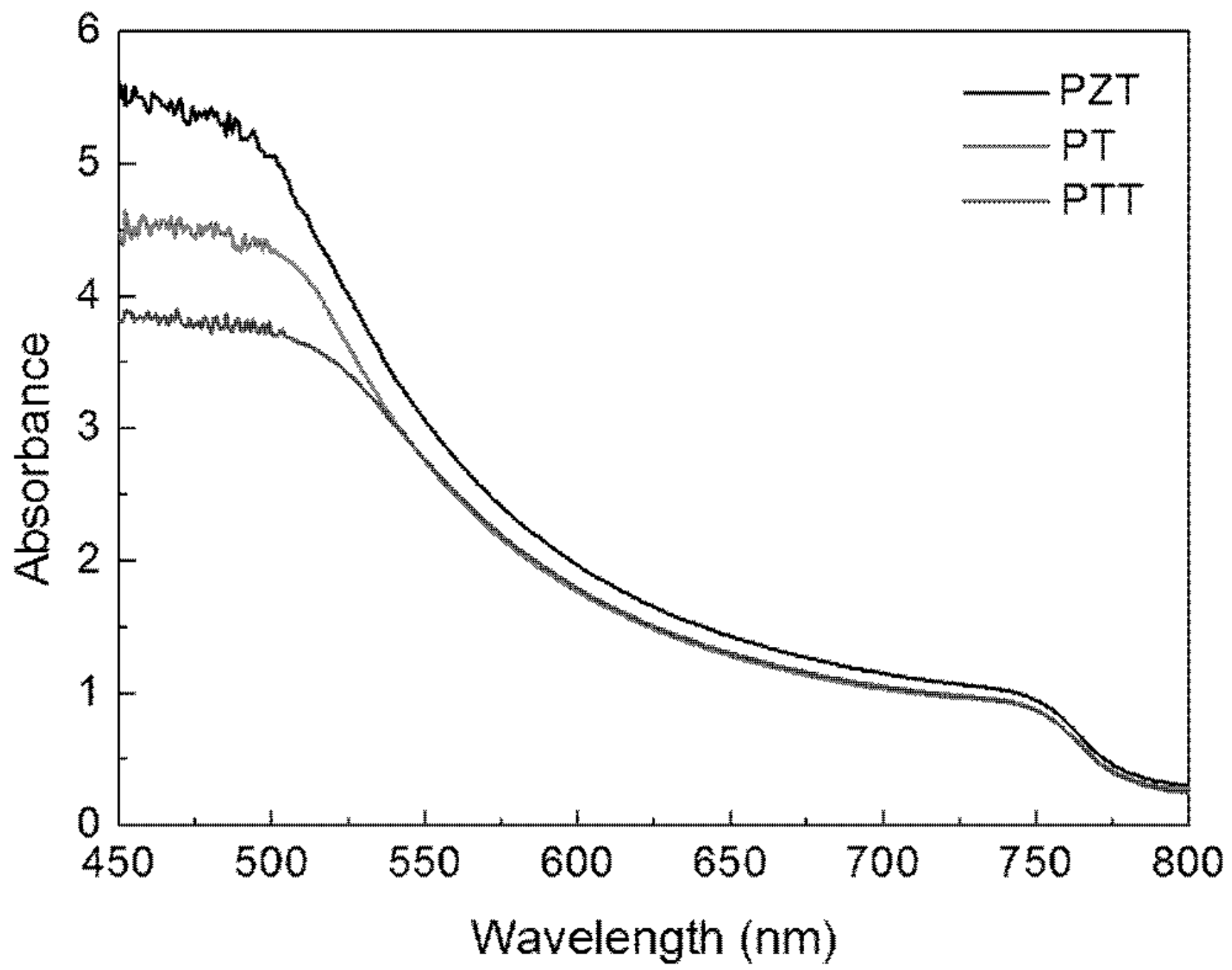

Figure 8

UV/vis absorbance spectra of PZT, PT and PTT film. 

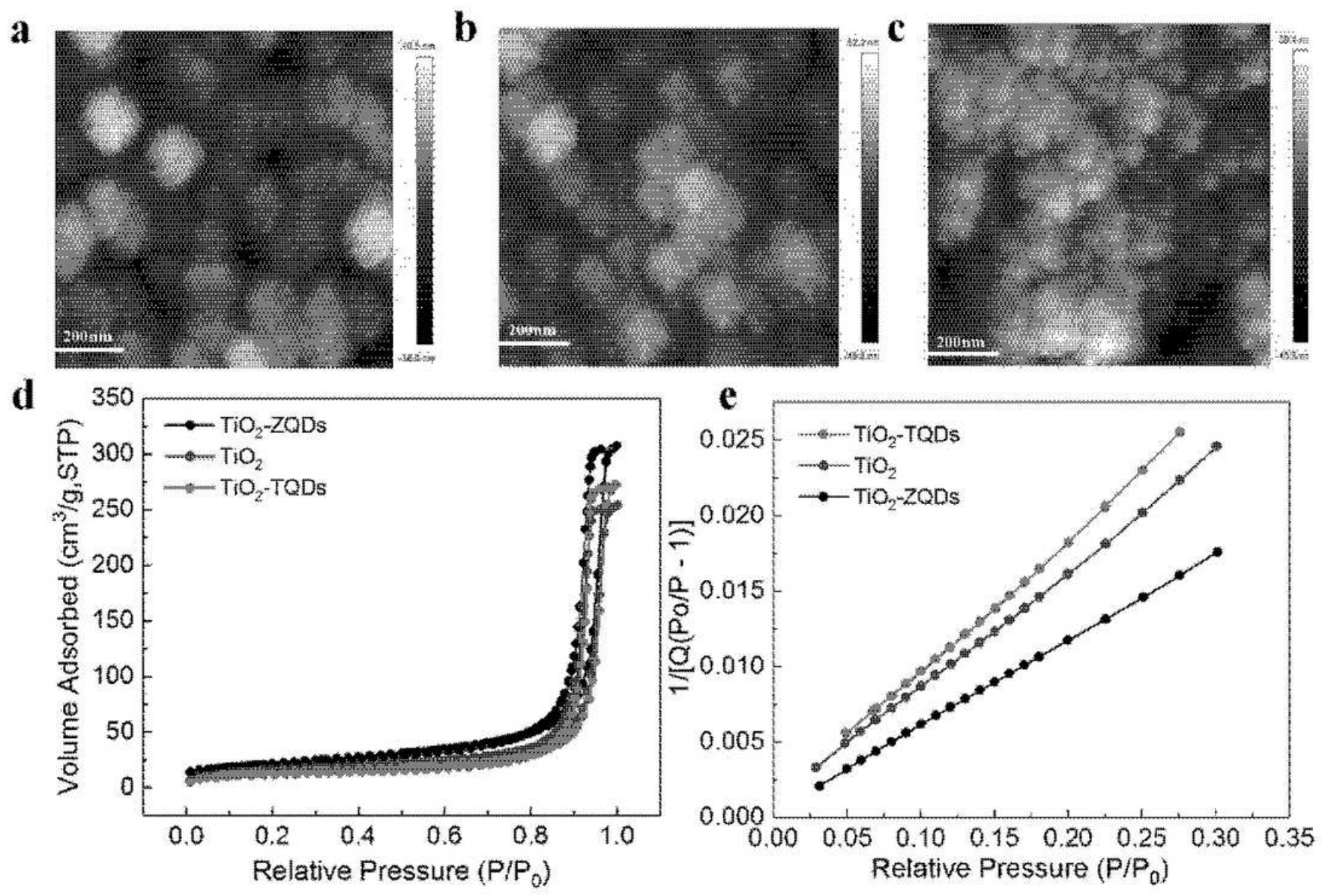

\section{Figure 9}

Top-view AFM images of (a) the pristine TiO2, (b) the ZQDs modified TiO2 and (c) the TQDs modified TiO2 film; (d) N2 adsorption-desorption isotherms and (e) BET surface area plot of the three kinds of mpTiO2. The AFM image sizes are all $1 \times 1 \mu \mathrm{m}$.
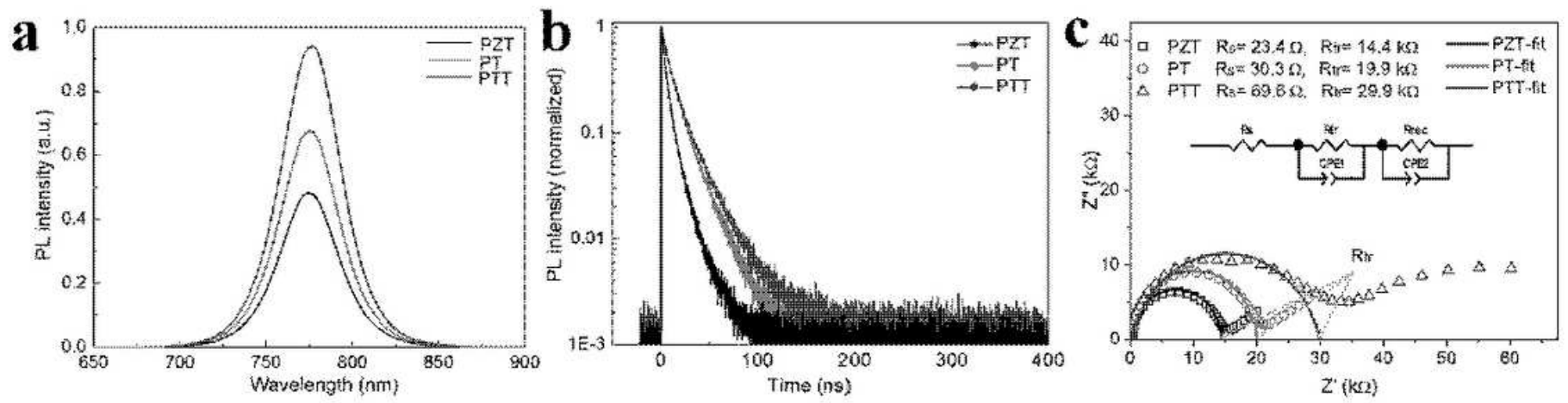

Figure 10

(a) PL spectra and (b) TRPL decay curves of the PT, PZT and PTT films; (c) the test Nyquist plots and the fitting curves of devices measured under ambient conditions in dark with a bias of $700 \mathrm{mV}$. The fitting curve is obtained according to the equivalent circuit in the inset. 


\section{Supplementary Files}

This is a list of supplementary files associated with this preprint. Click to download.

- GraphicalAbstract.tif

- SupportingInformationforPublication.pdf 